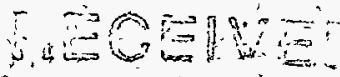 \\ DEC 2 \& 1395 \\ (19) $\leqslant$ ता
}

\section{Alternative Comparison, Analysis, and Evaluation of Solid Waste and Materials System Alternatives}
A. J. Brothers

September 1995

Prepared for the U.S. Department of Energy under Contract DE-AC06-76RLO 1830

Pacific Northwest Laboratory Operated for the U.S. Department of Energy by Battelle Miemorial Institute 
This report was prepared as an account of work sponsored by an agency of the United States Government. Neither the United States Government nor any agency. thereof, nor. Battelle Memorial Institute, nor any of their employees, makes any warranty, express or implied, or assumes äny legal liability or responsibility for the accuracy, completeness, or usefulress of any information, apparatus, product, or process disclosed, or represents that its use would not infringe privately owned rights.'Reference heréin to any specific cómmercial product, processs, or śervice by trade name, trademark; manufacturer, or otherwise does not necessarily constitute or imply-its endorsement, recommendation, or favoring by the United States Government or any, agency thereof, or Battelle Memorial institute. The views and opinions of authors expressed herein do riotnecessarily state or reflect those of the United States Govemment or any agency thereof:

PACIFIC NORTHWEST LABORATORY

$\because \quad$ operated by

BATTELLE MEMORIAL INSTITUTE-

UNITED STATES DEPARTMENT OF ENERGY under Contract.DE-AC06-76RLO 1830

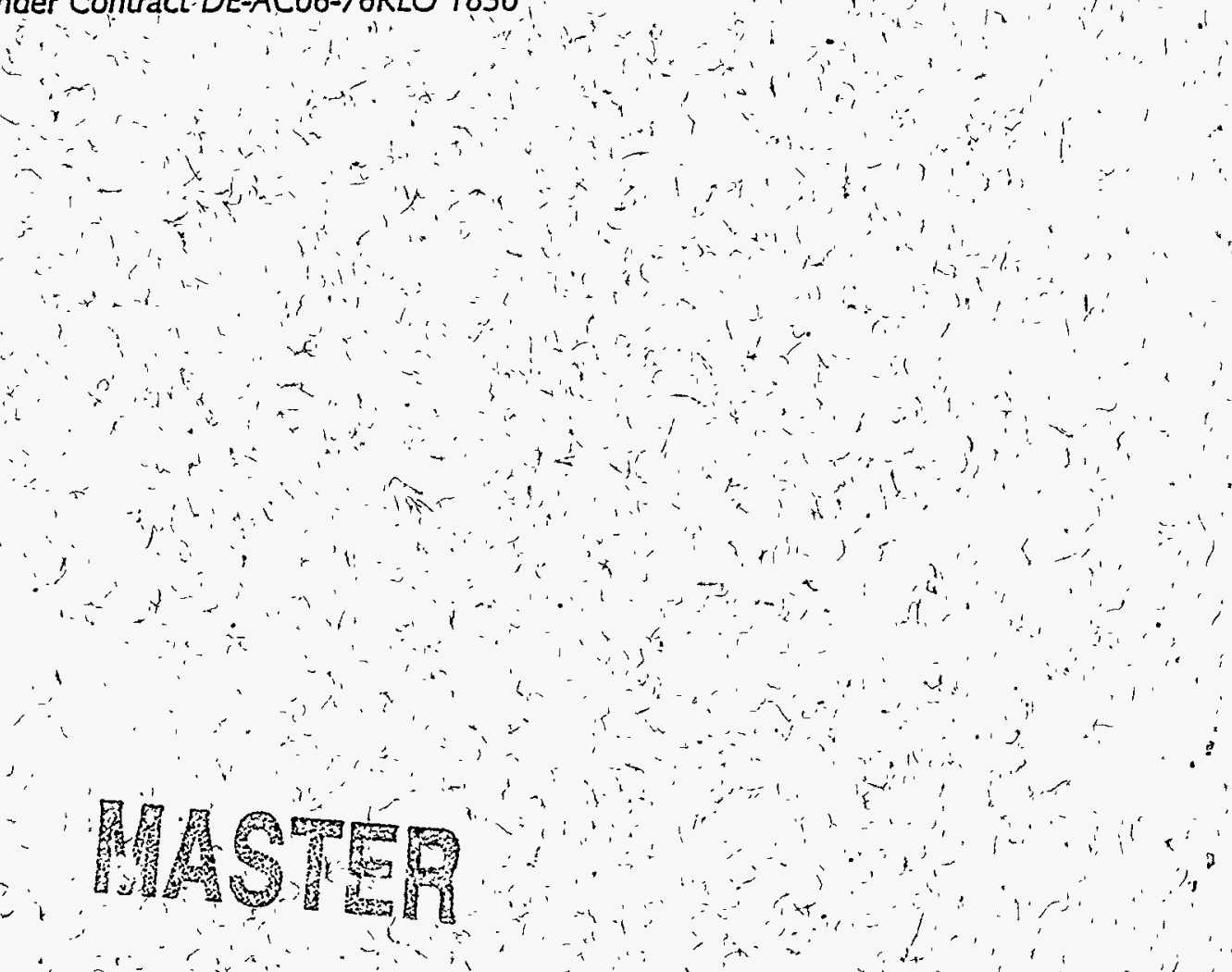

This document was printed on recycled pàper:t. 


\title{
Alternative Comparison, Analysis, and Evaluation of Solid Waste and Materials System Alternatives
}

\author{
A. J. Brothers
}

September 1995

Prepared for the U.S. Department of Energy under Contract DE-AC06-76RLO 1830

Pacific Northwest Laboratory

Richland, Washington 99352

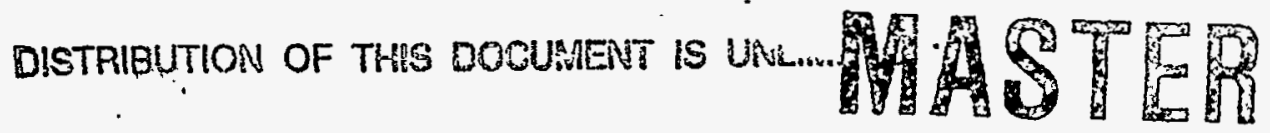





\section{Contents}

Acknowledgments $\ldots \ldots \ldots \ldots \ldots \ldots \ldots \ldots \ldots \ldots \ldots \ldots \ldots \ldots \ldots$

1:0 Introduction $\ldots \ldots \ldots \ldots \ldots \ldots \ldots \ldots \ldots \ldots \ldots \ldots \ldots \ldots \ldots$

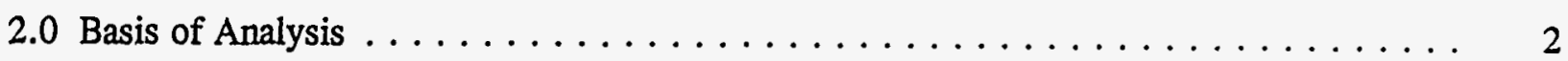

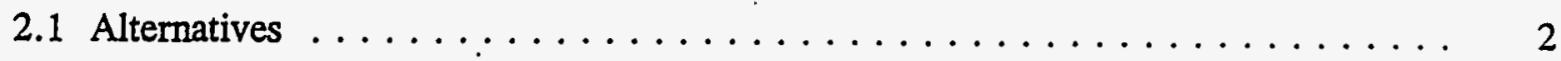

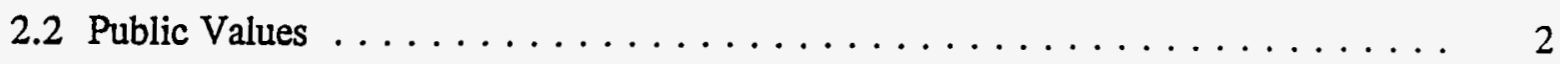

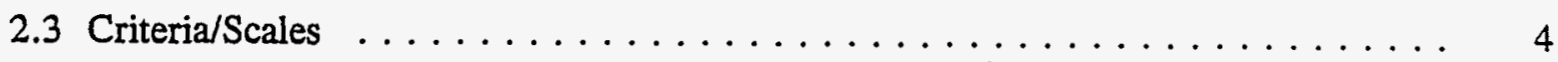

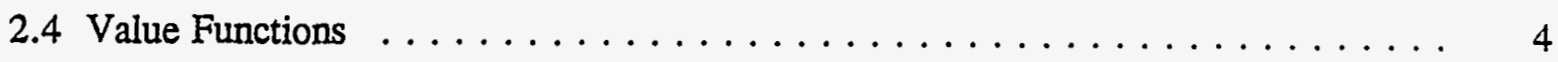

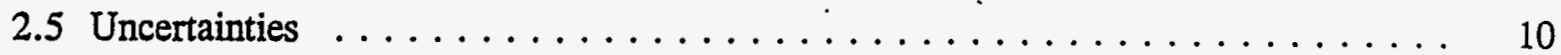

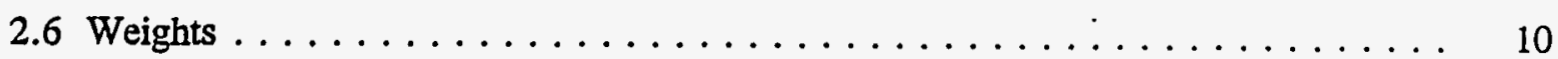

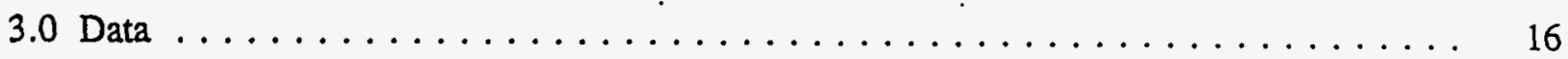

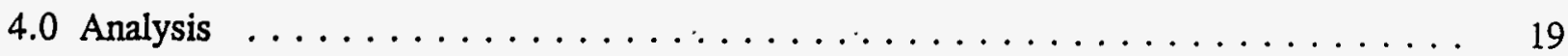

4.1 Overall Performance on Public Values $\ldots \ldots \ldots \ldots \ldots$

4.2 Overall Performance from Different Value Perspectives . . . . . . . . . . 20

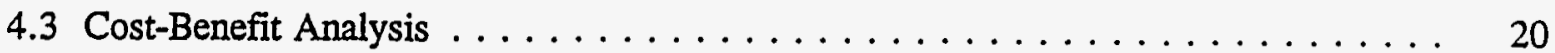

4.4 Detailed Analysis of Performance on Public Values . . . . . . . . . . . . 23

4.5 Sensitivity Aralysis . . . . . . . . . . . . . . . . . . . 29

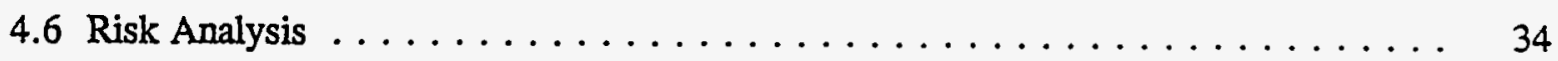

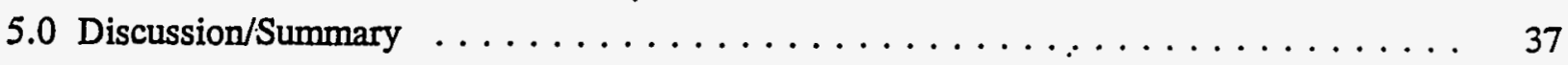

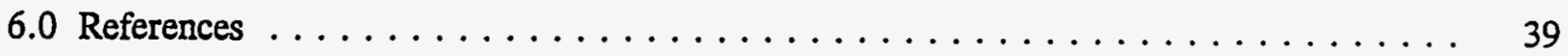




\section{Figures}

1 Public Values Used in the Analysis of Solid Waste Technical Options . . . . . . . . 3

2 Example Value Functions Used in Solid Waste Technical Options . . . . . . . . . . . 9

3 Decision Tree Showing Possible Scenarios Resulting in Impacts to Cost and Schedule . . . . . . . . . . . . . . . . . . . . . . . . . 11

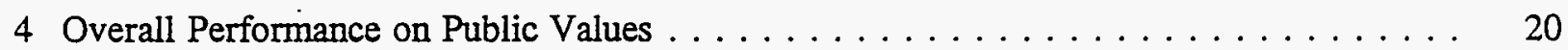

5 Analysis Comparison for Different Value Perspectives $\ldots \ldots \ldots \ldots \ldots \ldots$

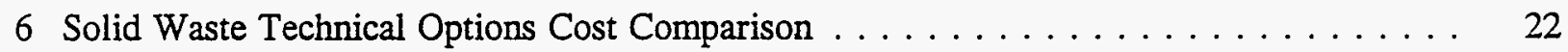

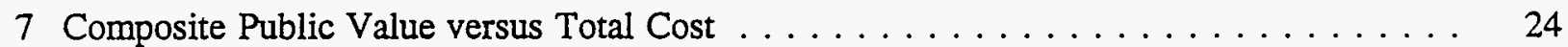

8 Composite Public Value versus Short-Term Capital Cost . . . . . . . . . . . . . 25

9 Composite Public Value versus Long-Term Capital Cost . . . . . . . . . . 26

10 Composite Public Value versus Maintenance and Operating Cost . . . . . . . . . . 27

11 Performance Profile for Solid Waste Technical Options . . . . . . . . . . . . . 28

12 Paired Comparisons of Technical Options on Individual Criteria $\ldots \ldots \ldots \ldots$

13 Sensitivity of Overall Public Value to Weights Placed on Specific Public Values . . . . . 32

14 Risk Profile for Cost of Technical Options $\ldots \ldots \ldots \ldots \ldots \ldots$

15 Risk Profiles for Schedule for Technical Options $\ldots \ldots \ldots \ldots$

16 Composite Public Value versus Total Cost Using Risk Analysis Data and Value Perspective Ranges 


\section{Tables}

1 Scales Used in the Analysis of Solid Waste Technical Options $\ldots \ldots \ldots \ldots$

2 Estimated Likelihood and Impacts of Regulatory Outcome . . . . . . . . . . . . 12

3 Estimated Likelihoods and Impacts of Unresolved Waste Processing Issues . . . . . . . 13

4 Estimated Likelihoods and Impacts of Funding Uncertainties $\ldots \ldots \ldots \ldots$

5 Weights Used in the Analysis of Solid Waste Technical Options . . . . . . . . . . . 14

6 Scores for Technical Options on Public Values Criteria . . . . . . . . . . . . . 17 



\section{Acknowledgments}

Thanks to Lorna Dirks, Alan Carison, Steve Smith, and Jack Kasper for their participation in developing the values, performance measures, and providing data. Also, thanks to Lorna Dirks for reading the manuscript and providing suggestions for improvement. Thanks to Ken Hladek for supporting a value analysis of this decision. Finally thanks to Don Haniey for his fine editing that greatly improved the readability of this paper. 
.

. 


\subsection{Introduction}

This paper presents a comprehensive analysis of the impact of solid waste technical options on values and objectives that are important to the public. It is written in support of the Solid Waste and Materials Systems Alternatives Study (WHC, 1995). Described are the values that were identified, the major programmatic risks, how the impacts were measured, the performance of alternatives, the methodology used for the analysis, the-results of the analysis, and the implications of the results.

Decision analysis was used to guide the collection and analysis of data and the logic of the evaluation. Decision analysis is a structured process for the analysis and evaluation of alternatives. It is theoretically grounded in a set of axioms that capture the basic principles of decision making (von Neuman and Morgenstern 1947). Decision analysis objectively specifies what factors are to be considered, how they are to be measured and evaluated, and their relative importance. The result is an analysis in which the underlying rationale or logic upon which the decision is based is made explicit. This makes possible open discussion of the decision basis in which facts and values are clearly distinguished, resulting in a well-documented decision that can be clearly explained and justified.

- The strategy of decision analysis is to analyze the various components relevant to the decision separately and then integrate the individual judgments to arrive at an overall decision. This assures that all the relevant factors are identified and their relative importance is considered. The procedure for obtaining the individual judgments, and the decision rules, for combining them and evaluating alternatives, have both theoretical and empirical foundation in mathematics, economics, and psychology.

Decision analysis makes use of numbers rather than qualitative expressions to construct scales, represent preferences, and express uncertainties. The relationship between qualitative preference structures and quantitative scales is given a precise and rigorous description in the discipline of measurement theory (Krantz et al. 1971), which is part of the theoretical foundation of decision analysis. An understanding of the logic of these relationships is especially important when there are multiple, possibly conflicting, objectives to be considered in the analysis. The standard reference for multiattribute decision analysis is Keeney and Raiffa (1970). Decision analysis also has formal procedures for considering uncertainty in the analysis. This makes it possible to evaluate the risks associated with each of the alternatives.

The steps in the decision analysis process are as follows:

\section{Describe Decision}

2. Identify Alternatives

3. Identify Objectives and Criteria and their Relationships

4. Evaluate Alternatives 


\section{Perform Sensitivity Analysis}

6. Select/Implement Alternative.

This is an iterative process in which some of the steps are interactive. The general framework holds whether one carries out a few simple calculations or an extremely complex and detailed analysis. The extent of the analysis is guided by the stakes involved and the difficulty of the decision. Time is also an important consideration. The objective of any analysis is to specify the decision basis and arrive at a clear course of action. A sound strategy is to error initially on the side of simplicity and extend the complexity of the analysis as necessary.

\subsection{Basis of Analysis}

This report describes the various components that formed the basis of the analysis presented in this paper.

\subsection{Alternatives}

The altematives chosen for this initial analysis are ones that bound the space of those available on the most salient dimensions. This initial selection of alternatives is designed to analyze strengths and weaknesses of alternatives and thus to exemplify the major tradeoffs. Alternatives interior to this space that are combinations of these can be evaluated in more detail at a later time.

The two major dimensions that this initial analysis focuses on are whether to emphasize the use of existing facilities or build new facilities, and whether the various processes should be combined in a single or common facility or a whether to use a modular approach in which the different processes are located in different buildings. Also included in the analysis is the Programs baseline. The specific realization of the combinations chosen for analysis are given detailed descriptions in the Solid Waste and Materials Systems Alternatives Study (WHC, 1995).

\subsection{Public Values}

Public values are the statements of what we want to achieve. Figure 1 shows the public values or objectives that, in part, form the basis for this analysis. These values result from a literature review summarized in Armacost et al. (1994), a series of workshops with technical personnel, and a review by program management. The objectives are intended to be an inclusive set that captures all the concerns of the public stakeholders, the Department of Energy, and WHC. The values have been tailored for the specific application of the solid waste and materials facility options, and have measurable scales that clearly define the degree to which the objectives are achieved. The degree to which a technical option achieves these values is considered to measure the extent to which the solid waste and materials facility's performance is maximized for all areas of public concern. 


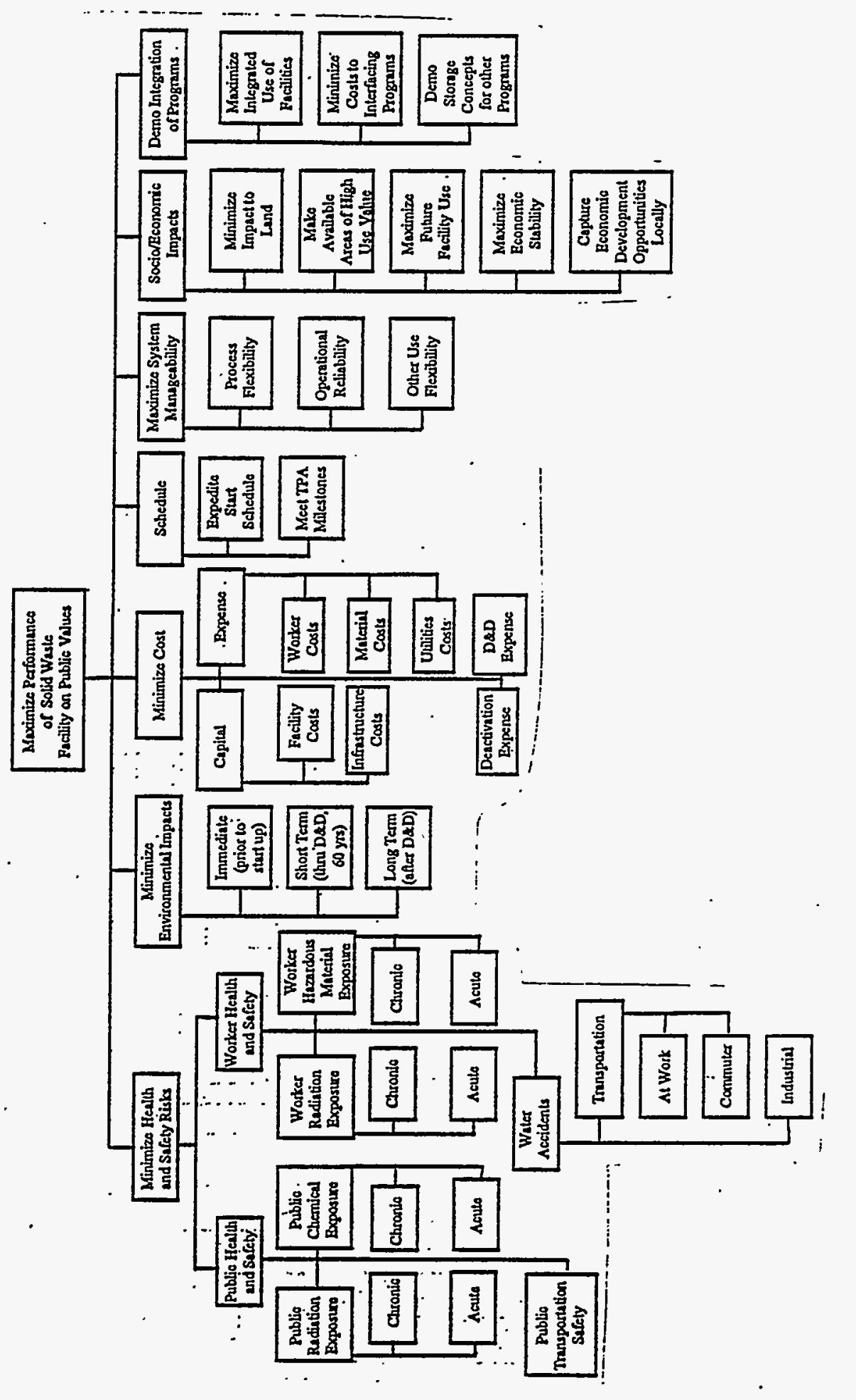

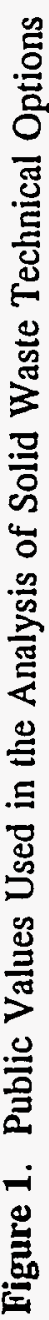


The identified areas of public concern, as shown in Figure 1, consist of maximizing public and worker health and safety, minimizing impacts to the environment, minimizing costs, expediting cleanup and meeting TPA milestones, as well as a consideration of socioeconomic impacts. Additional considerations are the manageability of the system and the integration of programs so as to promote overall efficiency and cost savings.

Each of these values has been further specified to capture all aspects of interest in the value. Thus, Health and Safety has been further specified as Public and Worker. Worker Health and Safety is further specified as "minimize worker radiation exposure," "minimize worker hazardous material exposure," and "minimize worker accidents." At each level of specification the value immediately above in the hierarchy is partitioned in a way that breaks out all aspects of the value while minimizing any overlapping. The specification of values was carried out until a level was arrived at that consisted of specific criteria for which a scale could be identified for precisely measuring the performance of each alternative. For example, worker radiation exposure was further specified as chronic and acute. The respective scales were the number of radiation workers, and the maximum number of individuals that could be exposed in a single incident. Scales are further described in the next subsection.

\subsection{Criteria/Scales}

The criteria or scales are the end points in the value hierarchy and make possible well-defined measurement of the degree to which the objectives are achieved. The scales have been selected with the alternatives in mind so as to make the collection of performance data reasonable considering the time and effort available. The scales used in the analysis are shown in Table 1.

Several types of scales are used in the analysis. The scales may be natural or constructed, and either type may be a proxy scale that provides an indirect measure of the value of concern (Keeney 1992). Natural scales are those that have a common, well-understood interpretation, and with a unit of measurement that people naturally associate with measurement. For example, "dollars" is a natural scale for the objective to minimize cost. "Miles" is also a natural scale, and is used in the analysis as a proxy scale for public radiation exposure. The distance in miles of the facilities from major population centers serves as an indirect measure for the objective to "minimize public radiation exposure."

The objective to "expedite start schedule" is measured by a constructed scale. This consists of a series of short scenarios or descriptions that represent different levels of performance on the objective. The scale for "expedite start schedule" considers both when facilities come on line and what percentage of processing capabilities are available. The numbers ranging from 0 to 100 that are associated with the constructed scales are value functions that capture the relative importance of different levels of performance. Value functions are further described in the next section.

\subsection{Value Functions}

Value functions were assessed to measure the relative importance of different levels of performance on.each of the criteria. Value functions take as their domain the various levels of performance as 


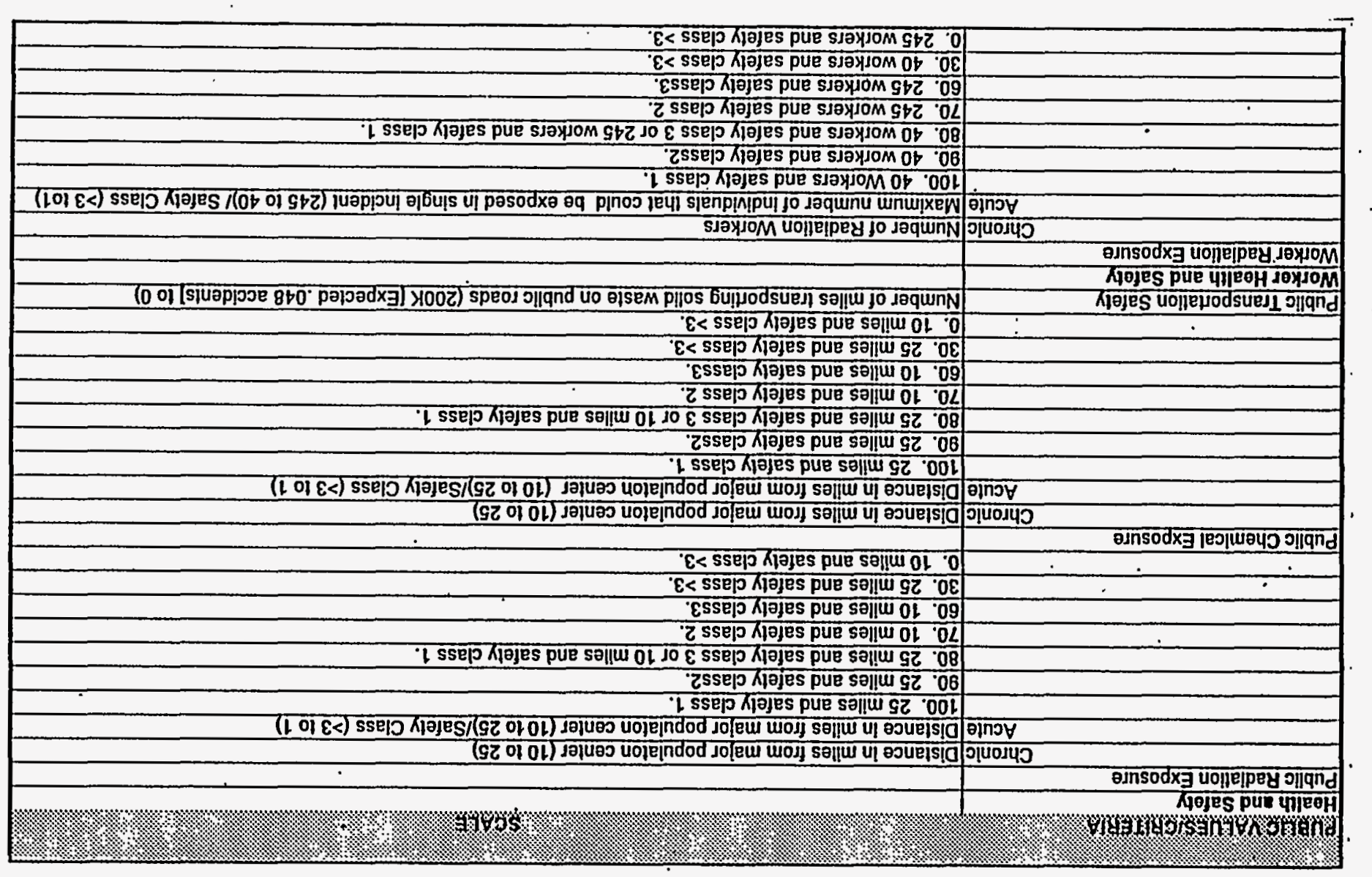

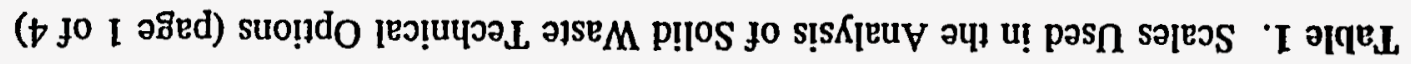




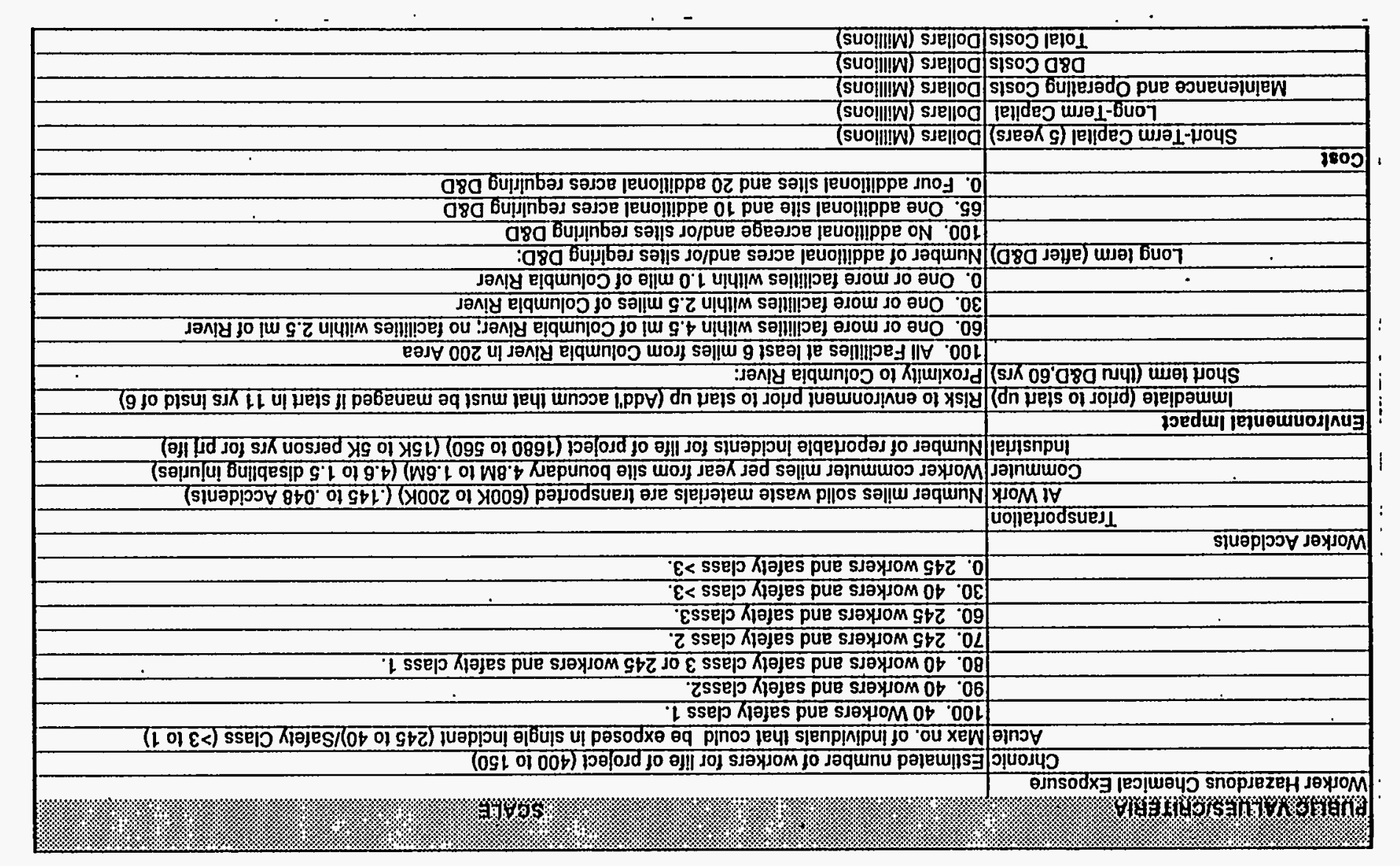

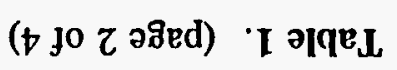




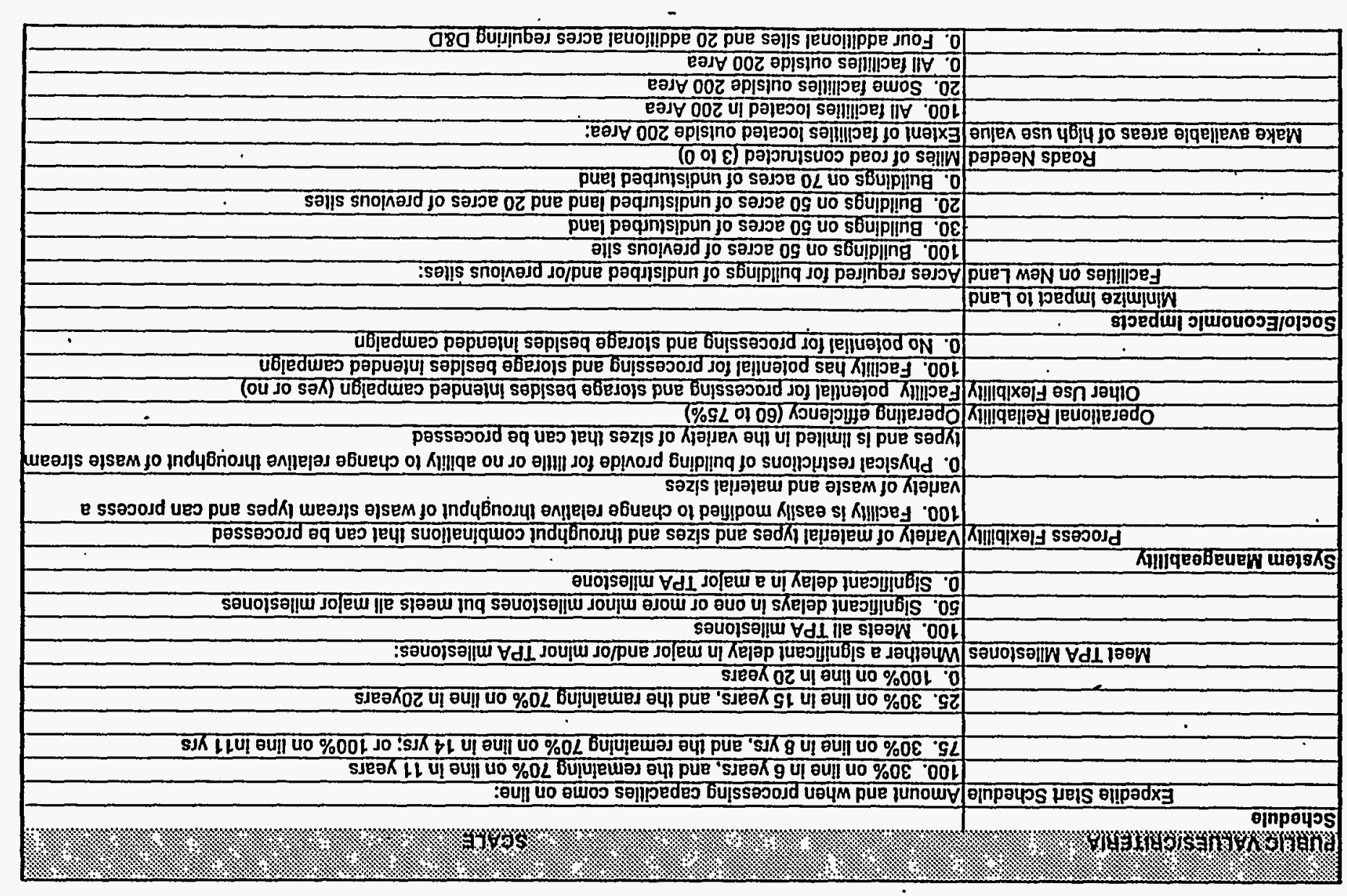

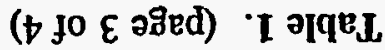




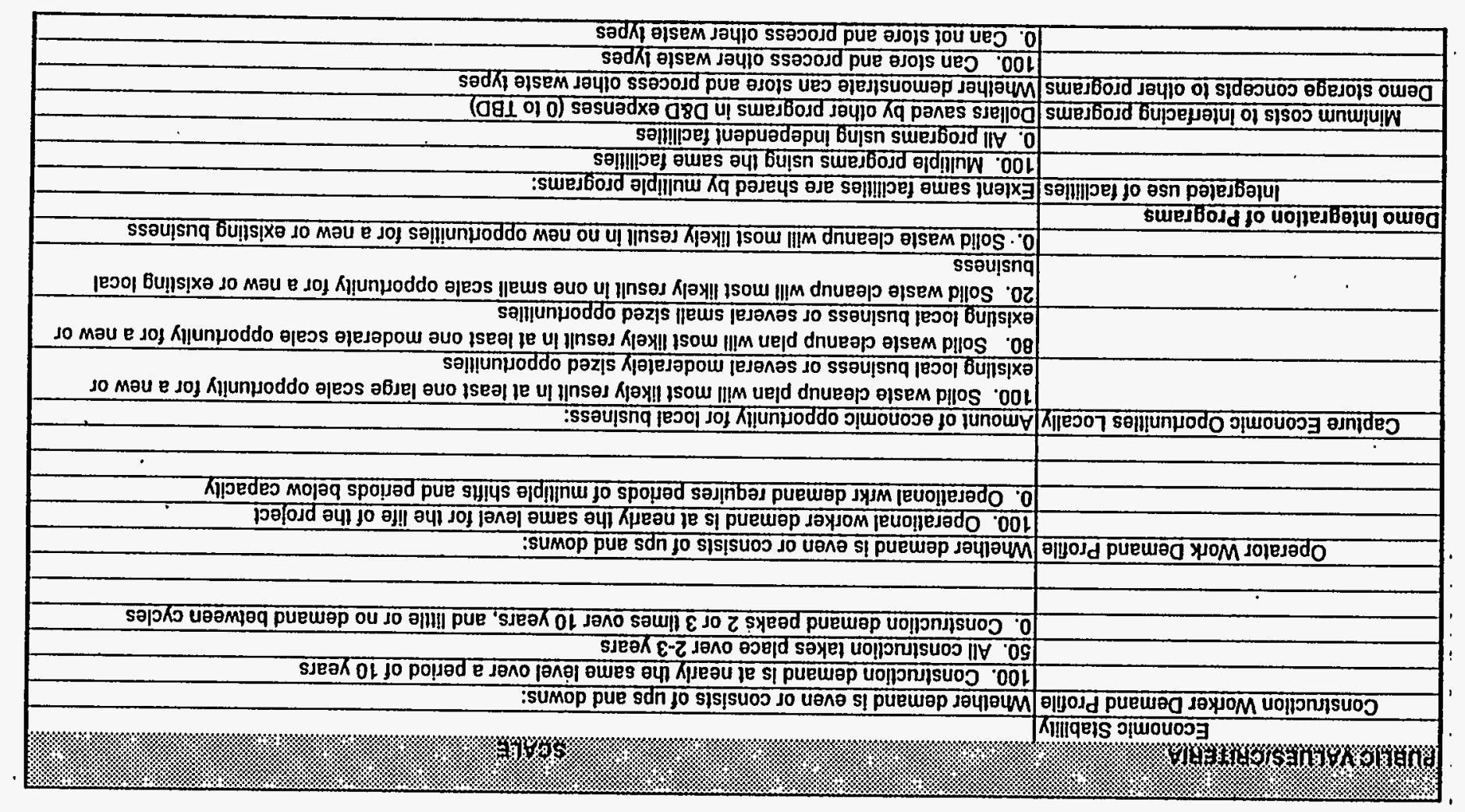

$\infty$

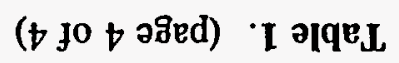


measured by the scales and map it onto either the unit interval or a 0-to-100 range. Value functions capture the fact that the importance of achieving different levels on an objective may not be linear with its scale. For example, the importance of distance as a measure of the potential for acute radiation exposure is not linear with distance because the dispersion of a potential release is not itself linear with distance. Value functions were developed based upon discussions among the engineers and the analyst. For criteria having constructed scales, each level of performance, as described by a scenario was assigned a number from 0 to 100 representing the relative importance of achieving that level of performance. These numbers are shown in Table 1. For criteria having natural scales; the value functions were judged to be linear with the measure. These were either increasing or decreasing functions depending on whether more was better or worse than less. Typical value functions are shown in Figure 2.

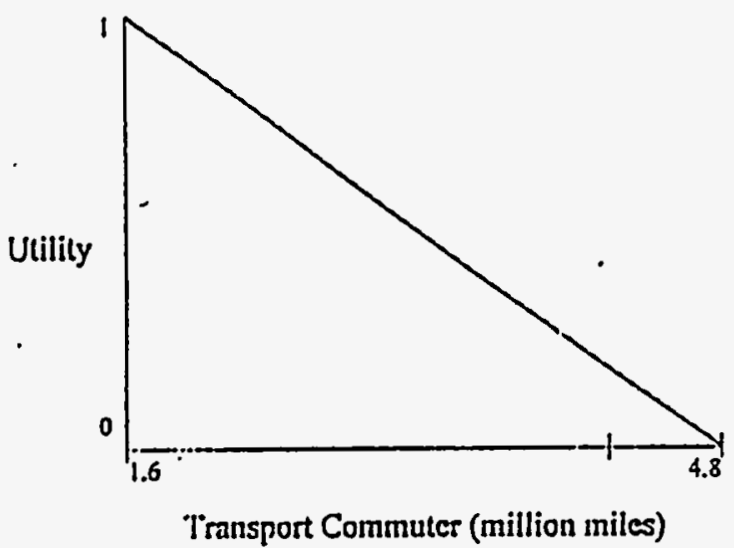

Transport Commuter (million miles)

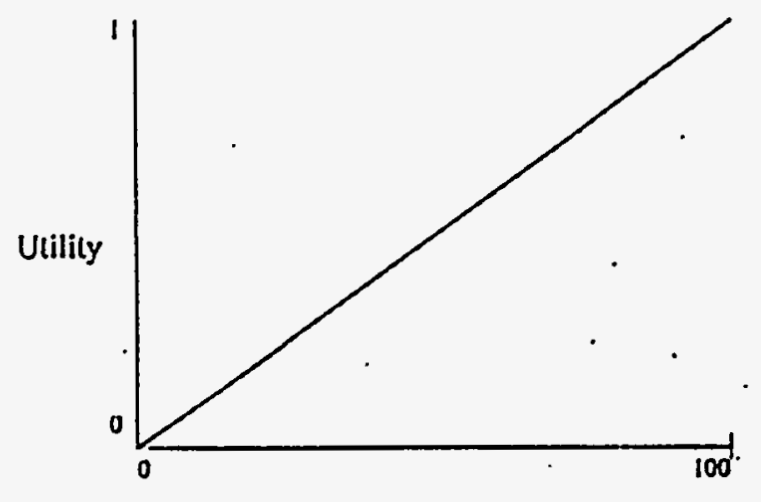

Mect TPA Milestones (constructed)
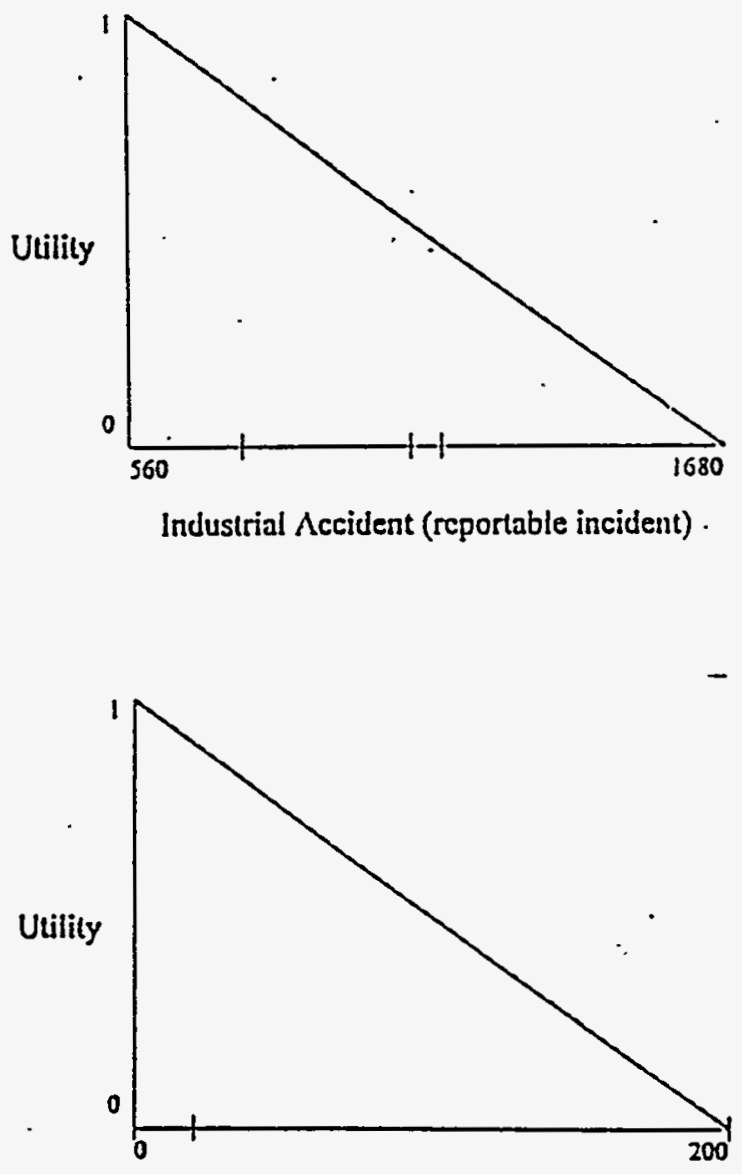

Pub Trms Sny (K miles)

Figure 2. Example Value Functions Used in Solid Waste Technical Options 


\subsection{Uncertainties}

For some objectives, alternative performance on objectives depends not only on the choice of the alternative, but on uncertainties that can not be directly controlled. Uncertainty is an important consideration in evaluating programmatic risk. Not all uncertainties warrant the same level of consideration. For much of the information, there may be uncertainty in the estimates, and if these uncertainties are symmetrically distributed, and independent of alternatives, there would not be noticeable differences if the results are based on point estimates. Uncertainties having asymmetric distributions require special consideration when estimating means. Uncertainties can be evaluated in more detail if sensitivity analysis warrants their further consideration. Of particular interest initially, are the uncertainties in which the outcome probabilities are not independent of the alternatives, and the uncertainties are thought to have a significant impact on the objectives or public values being considered in the decision.

Three such uncertainties have been identified. They are the regulatory outcome, the resolution of issues surrounding waste processing, and the feasibility of capital funding.

- Regulatory outcome refers to permitting issues, and has the potential of significant impacts on schedule and costs.

- Waste processing has unresolved issues concerning container requirements, cask requirements, and other handling criteria. The potential impact of a delay in resolving these issues is judged to be greater for a common facility than for a modular facility.

- Capital funding has a longer project cycle for larger projects and is more uncertain; consequently, alternatives using a common facility have a greater likelihood for delays in funding or not being funded at all.

These uncertainties are represented in the analysis by a decision tree shown in Figure 3. The tree is read from left to right. The square node on the left represents the four possible decision paths; the circles represent potential paths for the uncertainty outcomes. The tree is shown in "schematic form." There are actually $4 \times 4 \times 2 \times 3=96$ possible paths through the tree. Each of the four alternatives will result in some performance level for all the values and criteria described in preceding sections. The impact of the uncertainties on these values is primarily to cost and schedule. The probabilities for each of the uncertain variables are assumed to depend on the alternatives shown, and to be independent of each other. The impacts on cost and schedule were estimated separately for each uncertainty. These estimates are shown in Tables 2 through 4.

\subsection{Weights}

Whereas value functions capture the importance of different levels of performance on a single objective, weights capture the relative importance of the different objectives or values. For example, weights answer the question of whether the potential impacts of chronic hazardous chemical exposure 


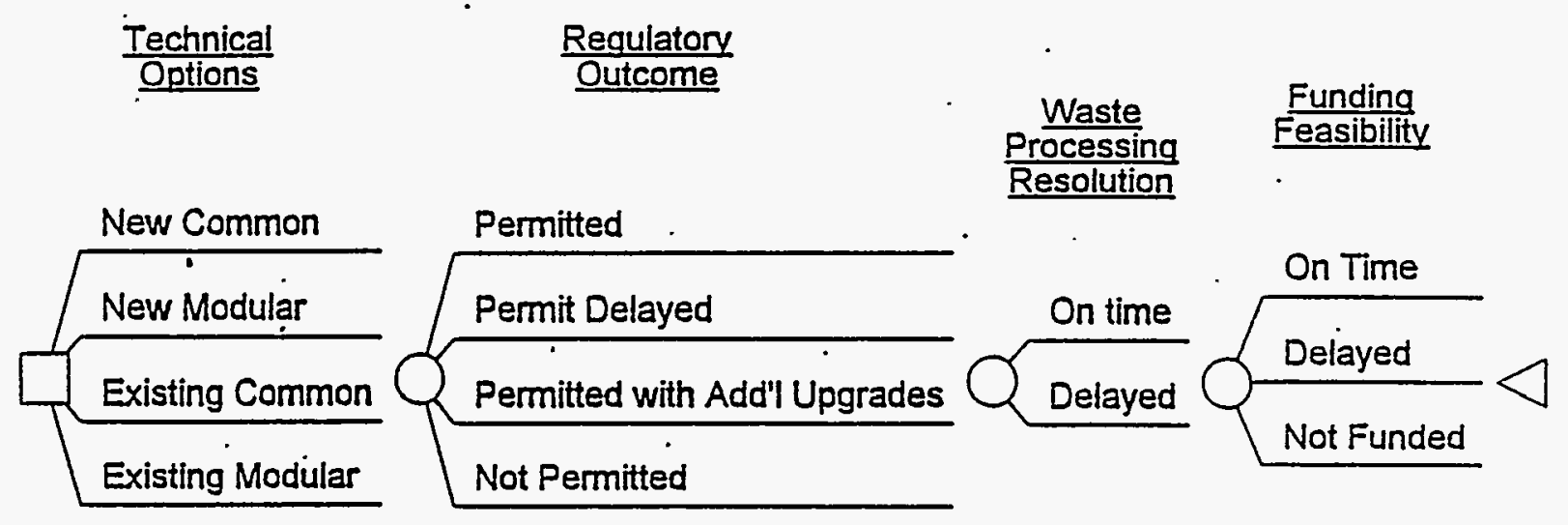

Figure 3. Decision Tree Showing Possible Scenarios Resulting in Impacts to Cost and Schedule

are more important to consider than those from acute hazardous chemical exposure. Weights logically depend on the potential ranges over which the alternatives can vary. A common error is to specify weights in a "top down" process without considering potential ranges of impacts. The method used to develop the weights in this study tied the importance of objectives to their ranges in a "bottom up" assessment process.

The methodology used for determining the relative weights is a standard decision analysis procedure known as "swing weighting." The resulting weights reflect the tradeoffs among the objectives in their respective units. The procedure requires that the set of criteria within each category or subcategory be first ordered according to rank, and then the ratios of relative importance are determined. Evaluators are asked to consider a situation in which a hypothetical alternative would score at the worst level for all criteria within a particular category. They are then asked to imagine that if that alternative could be improved to the best level on one criterion, which criterion would be their first choice for the improvement, the second choice, etc. This provides a basis for the rankings. Ratio judgments of relative importance are then obtained. The process is repeated for each of the categories, and then extended to obtain judgements across categories. The importance ratios are then normalized so that the weights across all categories sum to one.

Weights were elicited independently from four engineers/managers who are knowledgeable about the solid waste program and are sensitive to stakeholder issues. Weights represent value judgments; consequently, there is no "correct" answer as to the relative importance that should be given to various public values. This is in contrast to estimates of performance, which while they may not be currently known, are thought to have correct answers. Consequently, performance data are generally best obtained from the appropriate technical experts, while values should come from the stakeholders. However, some technical expertise is valuable in assessing weights because many of the scales are proxy scales, and expertise is necessary in order to consider the potential impact that these scales will have on the more fundamental objectives, which can not be measured directly. Those making the judgments attempted to adopt a public perspective rather than giving their personal opinion. 
Table 2. Estimated Likelihood and Impacts of Regulatory Outcome

\begin{tabular}{|c|c|c|c|c|}
\hline bechuncalopton & 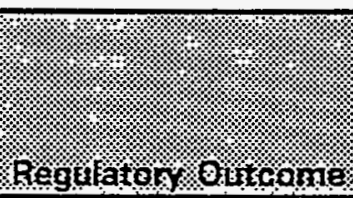 & Prob & 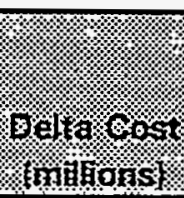 & Vistas befayed \\
\hline \multirow[t]{4}{*}{ New Common } & Permitted & 0.4 & 0 & 0 \\
\hline & Permits Delayed & 0.3 & 30 & 1 \\
\hline & Upgrades Required & 0.25 & 75 & 2 \\
\hline & Not Permitted & 0.05 & 300 & 10 \\
\hline \multirow[t]{4}{*}{ New Modular } & Permitted & 0.5 & 0 & 0 \\
\hline & Permit Delayed & 0.25 & 15 & 1 \\
\hline & Upgrades Required & 0.2 & 45 & 2 \\
\hline & Not Permitted & 0.05 & 130 & 10 \\
\hline \multirow[t]{4}{*}{ Existing Common } & Permitted & 0.5 & 0 & 0 \\
\hline & Permit Delayed & 0.25 & 18 & 1 \\
\hline & Upgrades Required & 0.2 & 51 & 2 \\
\hline & Not Permitted & 0.05 & 72 & 10 \\
\hline \multirow[t]{4}{*}{ Existing Modular } & Permitted & 0.6 & 0 & 0 \\
\hline & Permit Delayed & 0.2 & 5 & 1 \\
\hline & Upgrades Required & 0.15 & 25 & 2 \\
\hline & Not Permitted & 0.05 & 30 & 10 \\
\hline
\end{tabular}

No attempt was made in the weight elicitation to trade off public values against dollar costs. The analysis will use the elicited weights to arrive at an overall public value score for each technical option and then directly compare performance on public value with cost. This method of analysis makes it possible to identify dominating options; that is, technical options that provide more value for less cost. It also keeps visible the cost-performance tradeoffs among the dominating options. Thus, the readers can judge for themselves whether the higher performing options are worth the additional cost.

The weights resulting from the elicitation are shown in Table 5. The first column in the table shows the major public values, in bold, along with the subcriteria. The next four columns show the weights obtained from each of the four experts. Each column shows the weights for the major public values, in bold, as well as weights for the specific subcriteria. Both the bold numbers and the non-bold numbers sum to one. Thus, the bold numbers capture the relative importance of the major criteria, and the non-bold numbers give the relative importance of specific criteria across all categories.

As can be seen in Table 5, three of the individuals' value weights were similar-at least for the major categories. A fourth individual brought a different value perspective, placing more weight on environmental impact and schedule and less weight on health and safety. In this person's judgment the potential impact on health and safety was not very large; consequently, less weight was placed upon it. 
Table 3. Estimated Likelihoods and Impact of Unresolved Waste Processing Issues

\begin{tabular}{|c|c|c|c|c|}
\hline 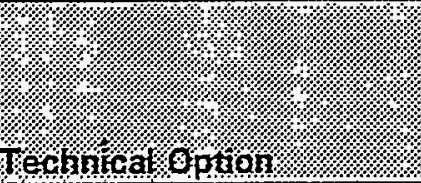 & 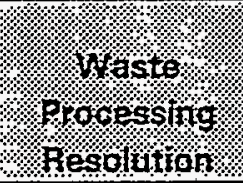 & rook & encingrost & 14ars: \\
\hline \multirow[t]{2}{*}{ New Common } & Resolved & 0.4 & 0 & 0 \\
\hline & Not Resolved & 0.6 & 150 & 5 \\
\hline \multirow[t]{3}{*}{ New Modular } & Resolved & 0.4 & 0 & 0 \\
\hline & Not Resolved & 0.6 & 65 & 5 \\
\hline & & & & . \\
\hline \multirow[t]{2}{*}{ Exiting Common } & Resolved & 0.4 & 0 & 0 \\
\hline & Not Resolved & 0.6 & 36 & 5 \\
\hline \multirow[t]{2}{*}{ Existing Modular } & Resolved & 0.4 & 0 & 0 \\
\hline & Not Resolved & 0.6 & 15 & 5 \\
\hline
\end{tabular}

Table 4. Estimated Likelihoods and Impacts of Funding Uncertainty

\begin{tabular}{|c|c|c|c|c|}
\hline irechircal optron & 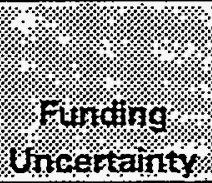 & Tols & Peltacoss & 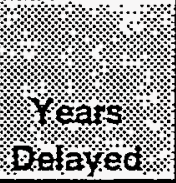 \\
\hline \multirow{3}{*}{ New Common } & On Time & 0.1 . & 0 & 0 \\
\hline & Delayed & 0.4 & 150 & 5 \\
\hline & Not Funded & 0.5 & 300 & 10 \\
\hline \multirow{3}{*}{ New Modular } & On Time & 03 & 0 & 0 \\
\hline & Delayed & 0.4 & 65 & 5 \\
\hline & Not Funded & 0.3 & 130 & 10 \\
\hline \multirow{3}{*}{ Exiting Common } & On Time & 0.3 & 0 & 0 \\
\hline & Delayed & 0.4 & 36 & 5 \\
\hline & Not Funded & 0.3 & 72 & 10 \\
\hline \multirow[t]{3}{*}{ Existing Modular } & On Time & 0.3 & 0 & 0 \\
\hline & Delayed & 0.4 & 15 & 5 \\
\hline & Not Funded & 0.3 & 30 & 10 \\
\hline
\end{tabular}


Table 5. Weights Used in the Analysis of Solid Waste Technical Options (page 1 of 2)

\begin{tabular}{|c|c|c|c|c|c|c|c|}
\hline ২ & ST & $10 \%$ & 16 & 18 & Consonsus & \%rerag & spots \\
\hline Public Health and Safety & 0.25 & 0.28 & 0.12 & 0.23 & 0.25 & 0.22 & 0.16 \\
\hline \multicolumn{8}{|l|}{ Public Radiation Exposure } \\
\hline Chronic & 0.040 & 0.017 & 0.027 & 0.042 & 0.033 & 0.031 & 0.020 \\
\hline Acute & 0.081 & 0.111 & 0.045 & 0.065 & 0.085 & 0.075 & 0.051 \\
\hline \multicolumn{8}{|l|}{ Public Chemical Exposure } \\
\hline Chronic & 0.040 & 0.006 & 0.009 & 0.032 & 0.026 & 0.022 & 0.016 \\
\hline Acute & 0.081 & 0.078 & 0.013 & 0.048 & 0.069 & 0.055 & 0.041 \\
\hline Public Transportation Safety & 0.008 & 0.067 & 0.022 & 0.045 & 0.040 & 0.036 & 0.024 \\
\hline Worker Health and Safety & 0.18 & 0.21 & 0.12 & 0.19 & 0.19 & 0.17 & 0.15 \\
\hline \multicolumn{8}{|l|}{ Worker Radiation Exposure } \\
\hline Chronic & 0.006 & 0.010 & 0.015 & 0.040 & 0.019 & 0.018 & 0.010 \\
\hline Acute & 0.044 & 0.069 & 0.030 & 0.032 & 0.049 & 0.044 & 0.038 \\
\hline \multicolumn{8}{|l|}{ Worker Hazardous Chemical Exposure } \\
\hline Chronic & 0.002 & 0.003 & 0.012 & 0.024 & 0.010 & 0.010 & 0.008 \\
\hline Acute & 0.044 & 0.049 & 0.024 & 0.024 & 0.039 & 0.035 & 0.030 \\
\hline \multicolumn{8}{|l|}{ Worker Accidents } \\
\hline \multicolumn{8}{|l|}{ Transportation } \\
\hline At Work & 0.011 & 0.042 & 0.018 & 0.017 & 0.023 & 0.022 & 0.018 \\
\hline Commuter & 0.033 & 0.021 & 0.003 & 0.034 & 0.029 & 0.023 & 0.022 \\
\hline Industrial & 0.035 & 0.014 & 0.018 & 0.032 & 0.027 & 0.025 & 0.021 \\
\hline Environmental impact & 0,08 & 0.14 & 0.23 & 0.17 & 0.13 & 0.16 & 0.18 \\
\hline Immediate (prior to start up) & 0.016 & 0.033 & 0.070 & 0.051 & 0.033 & 0.042 & 0.047 \\
\hline Short term (thru D\&D,60 yrs) & 0.033 & 0.066 & 0.046 & 0.073 & 0.057 & 0.054 & 0.080 \\
\hline Long term (after D\&D) & 0.026 & 0.040 & 0.116 & 0.051 & 0.039 & 0.058 & 0.055 \\
\hline
\end{tabular}


Table 5. (page 2 of 2)

\begin{tabular}{|c|c|c|c|c|c|c|c|}
\hline & S5. & 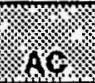 & 16 & 10 & Gon Avingus & r.cesto & 3ots \\
\hline Schedule & 0.20 & 0.13 & 0.29 & 0.12 & 0.15 & 0.18 & 0.15 \\
\hline Expedile Start Schedule & 0.111 & 0.104 & 0.193 & 0.089 & 0.102 & 0.124 & 0.104 \\
\hline Meet TPA Milestones & 0.089 & 0.021 & 0.097 & 0.027 & 0.046 & 0.058 & 0.047 \\
\hline System Manageability & 0.08 & 0.04 & 0.03 & 0.07 & 0.06 & 0.05 & 0.05 \\
\hline $\begin{array}{l}\text { Process Flexibility } \\
\end{array}$ & 0.016 & 0.020 & 0.018 & 0.028 & 0.022 & 0.021 & 0.016 \\
\hline Operational Reliability & 0.033 & 0.008 & 0.004 & 0.014 & 0.018 & 0.015 & 0.013 \\
\hline Other Use Flexibility & 0.026 & 0.014 & 0.007 & 0.027 & 0.022 & 0.019 & 0.016 \\
\hline & & & & & & & \\
\hline Soclo/Economic Impacts & 0.13 & 0.18 & 0.17 & 0.17 & 0.16 & 0.16 & 0.23 \\
\hline \multicolumn{8}{|l|}{ Minimize Impact to Land } \\
\hline Facilities on New Land & 0.025 & 0.040 & 0.064 & 0.034 & 0.033 & 0.041 & 0.047 \\
\hline Roads Needed & 0.012 & 0.006 & 0.019 & 0.008 & 0.009 & 0.011 & 0.013 \\
\hline Available areas of high use value & 0.025 & 0.057 & 0.013 & 0.032 & 0.038 & 0.032 & 0.054 \\
\hline & 0.020 & 0.003 & 0.000 & 0.012 & 0.011 & 0.009 & 0.016 \\
\hline \multicolumn{8}{|l|}{ Economic Stability } \\
\hline Construction Worker Demand Profile & 0.020 & 0.011 & 0.013 & 0.014 & 0.015 & 0.014 & 0.021 \\
\hline Operalor Worker Demand Profile & 0.010 & 0.034 & 0.039 & 0.040 & 0.028 & 0.031 & 0.040 \\
\hline Capture Economic Oportunity Locally & 0.015 & 0.029 & 0.026 & 0.036 & 0.026 & 0.026 & 0.037 \\
\hline Demo Integratlon of Programs & 0.10 & 0.03 & 0.04 & 0.05 & 0.06 & 0.05 & 0.09 \\
\hline Integrated use of facilities & 0.043 & 0.014 & 0.012 & 0.014 & 0.024 & 0.021 & 0.038 \\
\hline Minimum costs to interfacing progrms & 0.035 & 0.003 & 0.024 & 0.019 & 0.019 & 0.020 & 0.030 \\
\hline Demo storage concepts to olher programs & 0.022 & 0.011 & 0.007 & 0.014 & 0.015 & 0.013 & 0.024 \\
\hline
\end{tabular}


The last three columns in Table 5 are averages. Column six displays a consensus average, which is the average of the three individuals with similar weights. Column seven presents average weights for all four individuals. The last column, "Grp/Avg," shows a group average obtained at a solid waste management meeting. The weights elicited in that meeting were at the level of the major categories only--subcategories were not considered. Consequently, the weights shown are those obtained at the meeting for major categories, with the relative importance within categories being taken from the consensus average. It should also be pointed out that for the weights obtained at the management meeting, there was no attempt to consider the range of potential impacts; that is, there was no attempt to trade off specific units.

The weights used in the following analysis are the consensus average weights. However, an analysis of the options' overall rankings was also carried out using the group/average weights as well as those for the individual with a different value perspective. These analyses are discussed further in Section 4.0

\subsection{Data}

The data used to evaluate the performance of solid waste technical options are in all cases based upon best engineering judgment. For some objectives detailed analysis was carried out to generate the data, and in other cases performance estimates were based upon direct engineering judgment. The performance of alternatives on the objectives is shown in Table 6 . This section provides an understanding of the basis for the data.

Potential for Public Exposure is based upon facility location and safety class. It is assumed that new facilities would be built to Class 3 standards. The existing WNP-1 facility was built to Class 1 standards. Public Transportation Safety is based upon the number of miles materials would be transported on public roads. This is based upon knowing facility and material locations and estimates of the number of shipments based on waste volumes.

Potential for Chronic Worker Exposure is based upon the total number of workers and the safety class. Acute exposures are based upon the number of workers located in a single facility; consequently, modular facilities score better on these measures. Worker Transportation Accidents--At Work is based upon the total number of miles for transporting materials. This is based on location of facilities and materials and estimates of number of trips. The range of $600 \mathrm{~K}$ mi to $200 \mathrm{~K} \mathrm{mi}$ was estimated to correspond to a potential of 0.145 to 0.045 accidents (National Safety Council, 1986). Worker Transportation Accidents-Commuter is based upon the number of commuter miles per year from the Site boundary. Worker Industrial Accidents is the number of reportable incidents. The range of 560 to 1680 reportable incidents corresponds to a range of $5 \mathrm{~K}$ to $15 \mathrm{~K}$ person-years for the life of the project (National Safety Council, 1986). 
Table 6. Scores for Technical Options on Public Values Criteria (page 1 of 2)

\begin{tabular}{|c|c|c|c|c|c|c|}
\hline 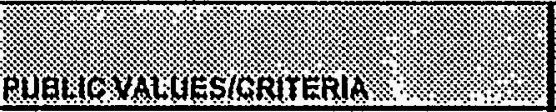 & 65\% & Solinion & Mowala & $\begin{array}{l}\text { Yexising } \\
\text { Montinat }\end{array}$ & 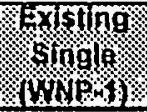 & Pograns \\
\hline & & & & & & \\
\hline \multicolumn{7}{|l|}{ Public Health and Safety } \\
\hline \multicolumn{7}{|l|}{ Public Radlation Exposure } \\
\hline Chronic & Miles (10-25) & 25 & 25 & 22 & 10 & 25 \\
\hline Acute & Miles (10-25)/Safety Class (>3 to 1) & $80(25 / 3)$ & $80(25 / 3)$ & $70(22 / 3)$ & $80(10 / 1)$ & $80(25 / 3)$ \\
\hline \multicolumn{7}{|l|}{ Public Chemical Exposure } \\
\hline Chronic & Miles (10-25) & 25 & 25 & 22 & 10 & 25 \\
\hline Acule & Miles $(10-25) /$ Safety Class $(>3$ to 1$)$ & $80(25 / 3)$ & $80(25 / 3)$ & $70(22 / 3)$ & $80(10 / 1)$ & $80(25 / 3)$ \\
\hline Public Transportation Safely & Miles (0-200K) & 0 & 0 & 20 & 200 & 0 \\
\hline \multicolumn{7}{|l|}{ Worker Health and Safety } \\
\hline \multicolumn{7}{|l|}{ Worker Radiation Exposure } \\
\hline Chronic & Rad Wrkrs & 249 . & 327 & 326 & 249 & 327 \\
\hline Acute & Wrkrs (245-40)/Safely Class ( $>3$ to 1$)$ & $60(245 / 3)$ & $80(116 / 3)$ & $70(154 / 3)$ & $80(245 / 1)$ & $70(154 / 3)$ \\
\hline \multicolumn{7}{|l|}{ Worker Hazardous Chemical Exposure } \\
\hline Chronic & Wrkrs (400 to 150) & 249 & 327 & 326 & 249 & 327 \\
\hline Acute & Wrkrs $(245-40) /$ Safely Class $(>3$ to 1$)$ & $60(245 / 3)$ & $80(116 / 3)$ & $70(154 / 3)$ & $80(245 / 1)$ & $70(154 / 3)$ \\
\hline \multicolumn{7}{|l|}{ Worker Accidents } \\
\hline \multicolumn{7}{|l|}{ - Transportation } \\
\hline At Work & Miles (600K to 200K) & 200 & 200 & 370 & 560 & 200 \\
\hline Commuter & Miles/yr $4.8 \mathrm{M}$ to $1.6 \mathrm{M})$ & 4.8 & 4.8 & 4.2 & 1.6 & 4.8 \\
\hline - Industrial & Reportable incidents & 776 & 1152 & 1094 & 776 & 1152 \\
\hline \multicolumn{7}{|l|}{ Environmental Impact } \\
\hline Immedlate (prior to start up) & Constructed $(0-100)$ & 0 & 80 & 100 & 100 & 40 \\
\hline Short term (thru D\&D,60 yrs) & Construcled $(0-100)$ & 100 & 100 & 92 & 30 & 95 \\
\hline Long term (after D\&D) & Constructed $(0-100)$ & 30 & 0 & 95 & 40 & 0 \\
\hline
\end{tabular}




\begin{tabular}{|c|c|c|c|c|c|c|}
\hline 0 & 001 & 001 & 0 & 001 & Tool-0) pejondisuoj & 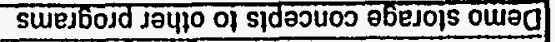 \\
\hline 0 & 0 & 009 & 0 & 0 & (W009 oi 0) panes sjellod & 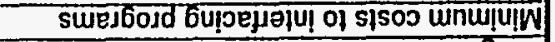 \\
\hline \multirow[t]{2}{*}{0} & 001 & 02 & 02 & 001 & 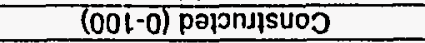 & 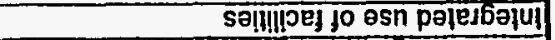 \\
\hline & & & & & & 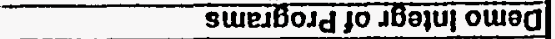 \\
\hline 08 & 001 & 02 & 08 & 001 & (001-0) pəónjistoo & 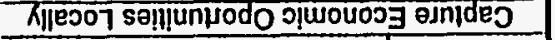 \\
\hline 001 & 001 & 001 & 001 & 001 & 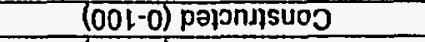 & өl!losd puewea seysom sojejado \\
\hline \multirow[t]{2}{*}{0} & 08 & 001 & 001 & 09 & $(001-0)$ pə)onjsuoj & 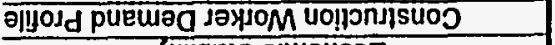 \\
\hline & & & & & & Xi!liqeis गumouorg \\
\hline 0 & $\mathbf{0}$ & 0 & 9 & $\underline{\mathbf{s}}$ & 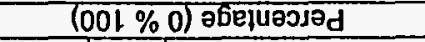 & esn Kn!!joed ouning \\
\hline 001 & 0 & 08 & 001 & 001 & (001-0) papnj!suoj & 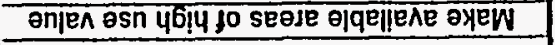 \\
\hline$\varepsilon$ & $\bar{z}$ & 1 & $\varepsilon$ & $z$ & $(001 \varepsilon)$ sal!W & pəpeөN speoy \\
\hline \multirow[t]{3}{*}{ o } & 001 & $\mathbf{G L}$ & 0 & 0 & (oot-0) papondisuos & pue 7 MEN Uo solnu!peg \\
\hline & & & & & & pue7 ol peduा вzјuịu, \\
\hline & & & & & & 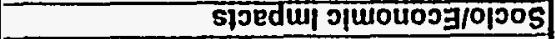 \\
\hline 0 & $\overline{0 L}$ & $\overline{0 S}$ & 001 & $\underline{G L}$ & (001-0) pajonjsuos & K!!! \\
\hline$O L$ & $\overline{0 L}$ & 02 & $0 L$ & $0 L$ & 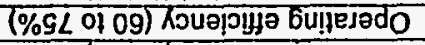 & Kinlqej|ey feuonjejado \\
\hline \multirow[t]{2}{*}{0} & 06 & $0 \mathrm{~g}$ & 001 & $\underline{G L}$ & 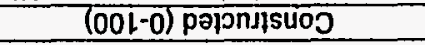 & 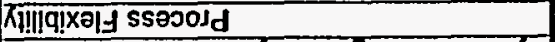 \\
\hline & & & & & & 7ylliqeobeuew woisks \\
\hline 001 & 001 & 001 & 001 & 001 & (001-0) pəoगnusuoo & satojsal!W VdL IOaW \\
\hline \multirow[t]{2}{*}{$\underline{\underline{S E}}$} & 001 & 001 & 001 & GL & 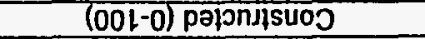 & 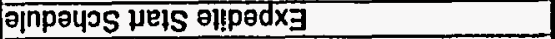 \\
\hline & & & & & & oppeyos \\
\hline $0+92$ & OESL & 0012 & 6998 & 1022 & (suo!n!w) sse|lo0 & 1500 18101 \\
\hline 002 & 002 & $0 \varepsilon>$ & $61 \varepsilon$ & $\varepsilon 82$ & (suo!lluw) siejlog & s1500 080 \\
\hline 026 & 008 & OEZL & $6 \angle Z !$ & 068 & (suo!lliw) slejlod & sjsoj buliejedo pue esueueluiew \\
\hline $08 E !$ & OEZ & 002 & 99L1 & 2921 & (suo!n!W) sJe\|loa & El!des uno1-6uo7 \\
\hline \multirow[t]{2}{*}{001} & $00 \varepsilon$ & 061 & 962 & $91 \varepsilon$ & (suo!lliw) sjejlog & 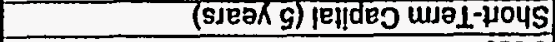 \\
\hline & & & & & & 1500 \\
\hline 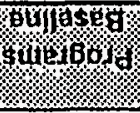 & 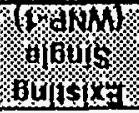 & 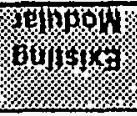 & 19nosh & \%1015: & SHIIS & 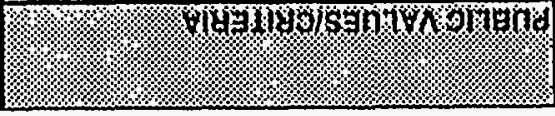 \\
\hline
\end{tabular}

( 
The immediate risk to the environment is based upon the additional accumulation that would occur if the start is 11 years hence instead of 6 years. Short-term risk to the environment is measured by the perceived risk resulting from facilities' proximity to the Columbia River. Long-term risk to the environment is captured by number of new acres and/or sites requiring D\&D.

All cost data are based upon detailed engineering analysis. System Manageability is based upon engineering judgment. Demonstrate Integration of Programs is also based upon engineering judgment, except for Minimize Cost to Interfacing Programs, which is based upon actual D\&D dollars saved.

Socioeconomic Impacts to the land and making available areas of High Future Use Value are based upon actual land needs and locations. Future Facility Use is based on engineering judgment of which facilities would have potential for commercial use at the end of project life. Economic Stability is based on planned times for construction and production estimates. Capture Economic Opportunities Locally is based upon engineering judgment.

\subsection{Analysis}

The data shown in Table 6 represent the facts used in the analysis of the solid waste technical options. No option scored best on all of the criteria; consequently, additional analysis is needed that considers costs and benefits and the judgments of tradeoffs among values. The following subsections analyze the strengths and weaknesses of the solid waste technical options.

Included are the results of the analysis of solid waste technical options' overall performance on public values. Performance on public values is considered from three different value perspectives. An analysis is presented of the cost-benefit tradeoffs, which reveals that three of the options are dominated; that is, other options provide more value for less cost. A detailed analysis is presented showing which specific criteria are driving the overall performance of the technical options on public value, and which criteria are the tradeoffs. An analysis is then presented that shows how robust each technical option's overall performance on public value is when changes are made in the relative importance assigned to major categories of public value. Lastly, a risk analysis is presented that examines the risk to cost and schedule caused by regulatory uncertainty, by the need to resolve waste-processing issues, and by funding uncertainties.

\subsection{Overall Performance on Public Values}

Figure 4 shows the overall scores for Maximizing Public Value for each of the five technical options. As can be seen in Figure 4, Existing Modular scored highest. New Modular and New Common were nearly tied for second, and the Program Baseline scored last. The overall scores were arrived at by taking the raw scores on each of the criteria and transforming them into a value from zero to one using the value functions for the criteria, and then taking a weighted sum of these values, where the weights used were the consensus average weights as described in this report. The resulting scores 


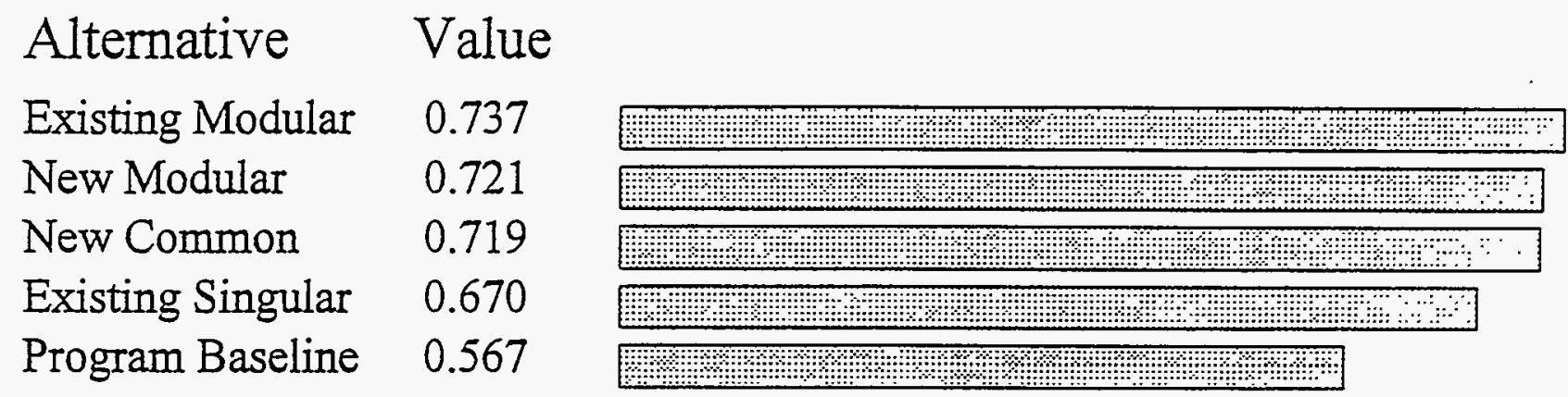

Preference Set $=$ Consensus Average

Figure 4. Overall Performance on Public Values

have a potential range from 0 to 1 , where 1 would indicate scoring the highest possible on all criteria, and 0 would resuit from the lowest score on all criteria. As can be seen in Figure 4 the scores ranged from 0.567 to 0.737 . These overall values do not consider cost. They are a weighted sum of all criteria with the exception of cost. Cost-benefit tradeoffs will be considered below. These values also do not consider risks to cost or schedule. These risks will also be analyzed below.

\subsection{Overall Performance from Different Value Perspectives}

The overall values shown in Figure 4 depend in part on the weights used to trade off the values. Three sets of weights were developed as described in this report. A comparison of the results using these three different value perspectives is shown in Figure 5. As can be seen in the figure all three value perspectives result in Existing Modular having the highest score and Programs Baseline having the lowest score. Thus, for each of the value perspectives there is agreement on which of the technical options performs best and which performs worst. There seems to be little consensus on the ranking of the remaining three alternatives from the different value perspectives. The one conclusion that might be drawn concerning these three alternatives (New Common, New Modular, and Existing Singular) is that they seem to be ranked relatively closely as compared with the Existing Modular and the Program Baseline Alternatives.

\subsection{Cost-Benefit Analysis}

The costs of the solid waste technical options are shown in Table 6. Costs were estimated for short-term capital (next 5 years), long-term capital (remaining capital after 5 years), maintenance and operating cost, and D\&D cost. Total cost is the summation of these four costs. This information is presented graphically in Figure 6. As seen in the figure, New Modular is the most costly overall and Existing Singular is the least costly. Maintenance and operating costs were estimated to be least for 


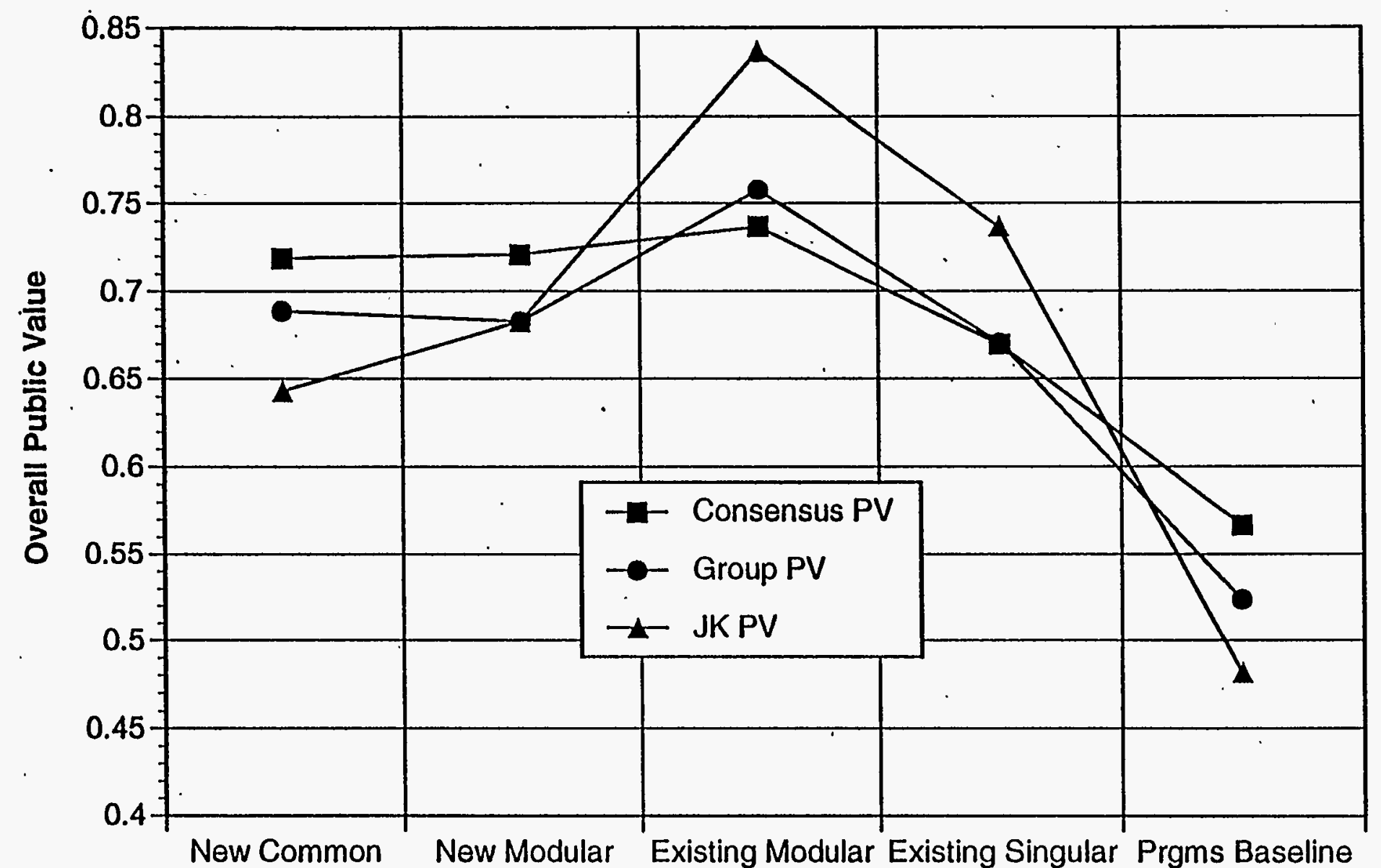

Facility Alternative

Figure 5. Analysis Comparison for Different Value Perspectives 


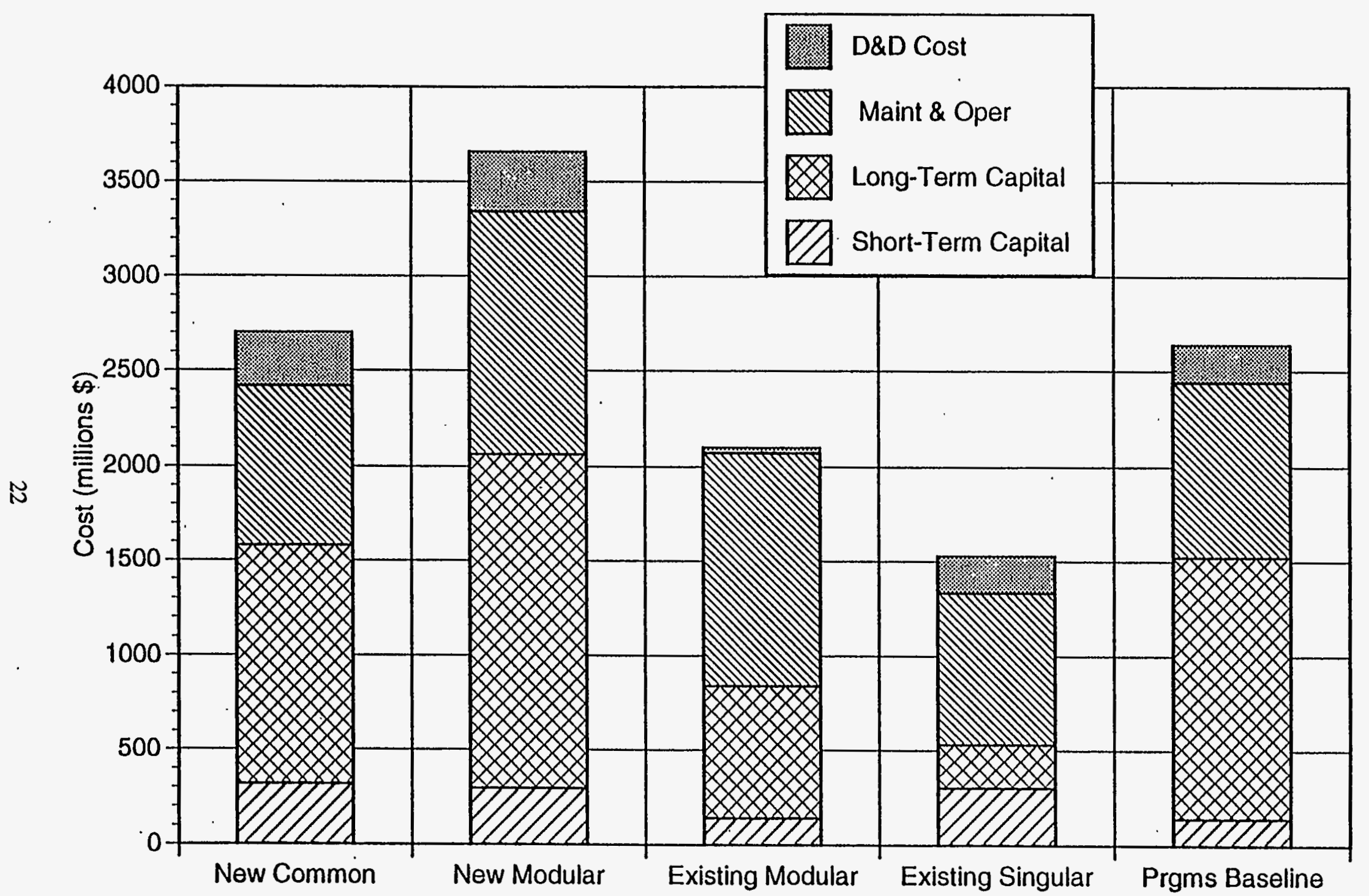

Figure 6. Solid Waste Technical Options Cost Comparison 
Existing Singular; however, it has the second highest short-term capital cost. Existing Modular, which had the highest overall performance, is the second least costly overall. It also ties for first in shortterm capital costs.

To show more clearly the relationship between costs and benefits, the options are plotted in a twodimensional cost $\mathrm{x}$ benefit space shown in Figure 7. The horizonal axis in Figure 7 is the total cost, and the vertical axis is the overall public value. The information shown in Figure 7 is extremely interesting. It shows that Existing Modular dominates New Common, New Modular, and Programs Baseline; that is, Existing Modular provides more overall value at less cost than these other three options. Existing Singular is not dominated by Existing Modular. Existing Singular provides less value, but it also costs less. Thus, when considering overall cost and overall public value, a decision must be made as to whether the additional benefits of Existing Modular are worth the additional cost. More detailed comparisons and analyses of the basis for the overall public value scores are presented in following subsections.

Figures 8 through 10 show similar plots for short-term capital costs, long-term capital costs, and maintenance and operating costs. Figure 9 for long-term capital costs shows the same pattern as for total costs; that is, Existing Modular dominates all options except Existing Singular. Figure 8 for short-term capital costs shows a similar pattern except that Existing Modular dominates all the options. Figure 10 for maintenance and operating costs tells a different story. Existing Modular is still the best performer, but New Common and existing Singular are also dominating options. So if maintenance and operating cost is a large consideration, then some thought should be given to whether Existing Modular is worth the additional expense as compared with New Common, and whether New Common is worth the additional cost over Existing Singular. The next section provides a more detailed analysis of what is driving the performance on overall public value for each of the technical options.

\subsection{Detailed Analysis of Performance on Public Values}

The overall values for the technical options depend on how they scored on the major public value categories and the weights given to those categories. This is depicted graphically in Figure 11. Figure 11 shows the performance profile for each of the five technical options. For each technical option, bars are shown for each of the major public value categories. (The ordering is such that socioeconomic impact is the third bar.) The weight given to a public value (which is the same for all the options) is represented by the bar's width. The option's performance or score for the public value is represented by the bar's height. Thus, the total area of all bars is the option's overall value.

Performance profiles show the relative strengths and weaknesses of each technical option. Recall that Existing Modular and Existing Singular were the two non-dominated options with respect to total cost (Figure 7). A comparison of these two technical options shows that Existing Modular scores better on Public Health and Safety, and worse on Worker Health and Safety. The scores are similar for Socioeconomic Impact and Schedule. Existing Modular does better on Environmental Impact and worse on System Manageability. Their scores were similar for Demonstrate Integration of Programs. 


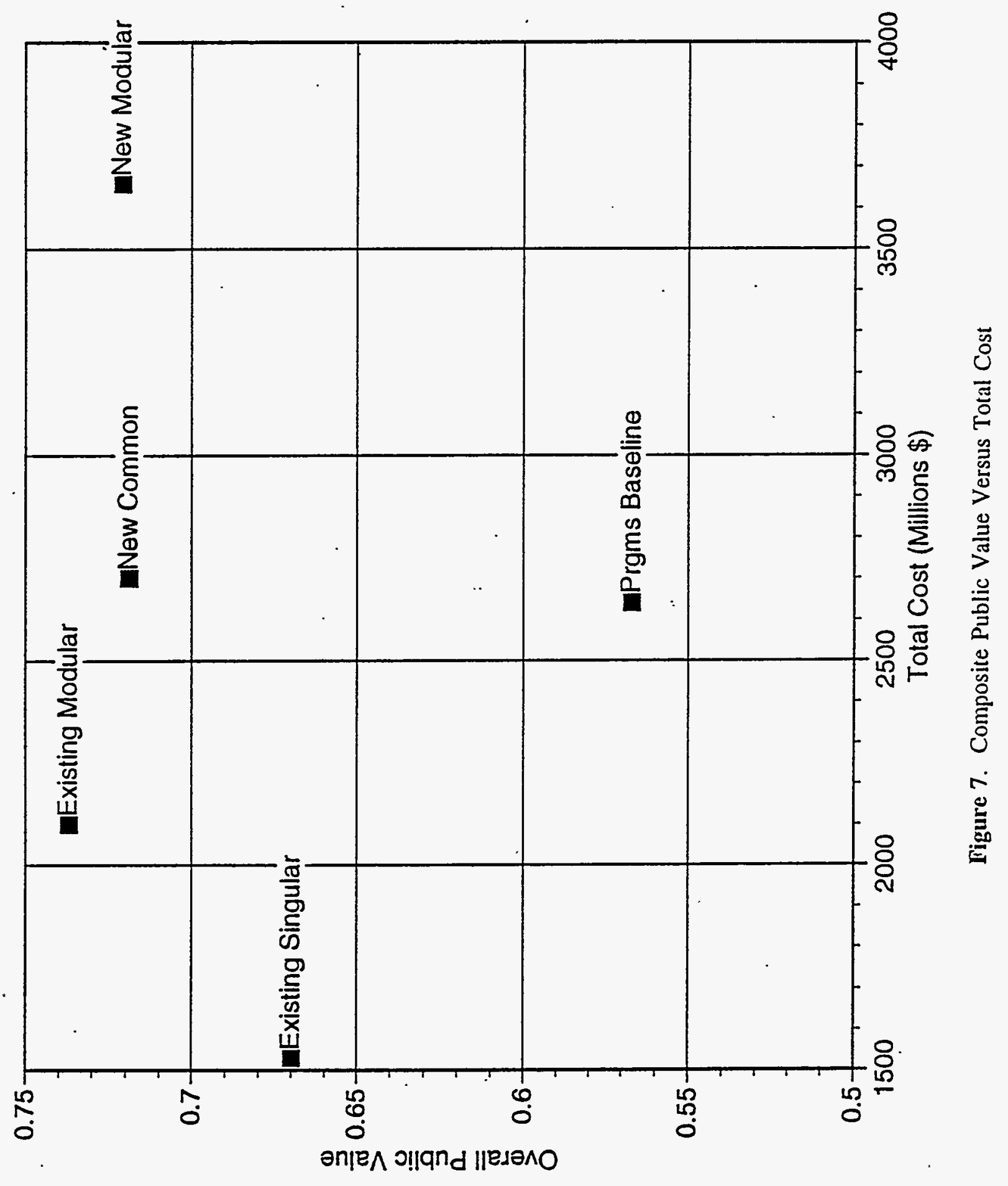




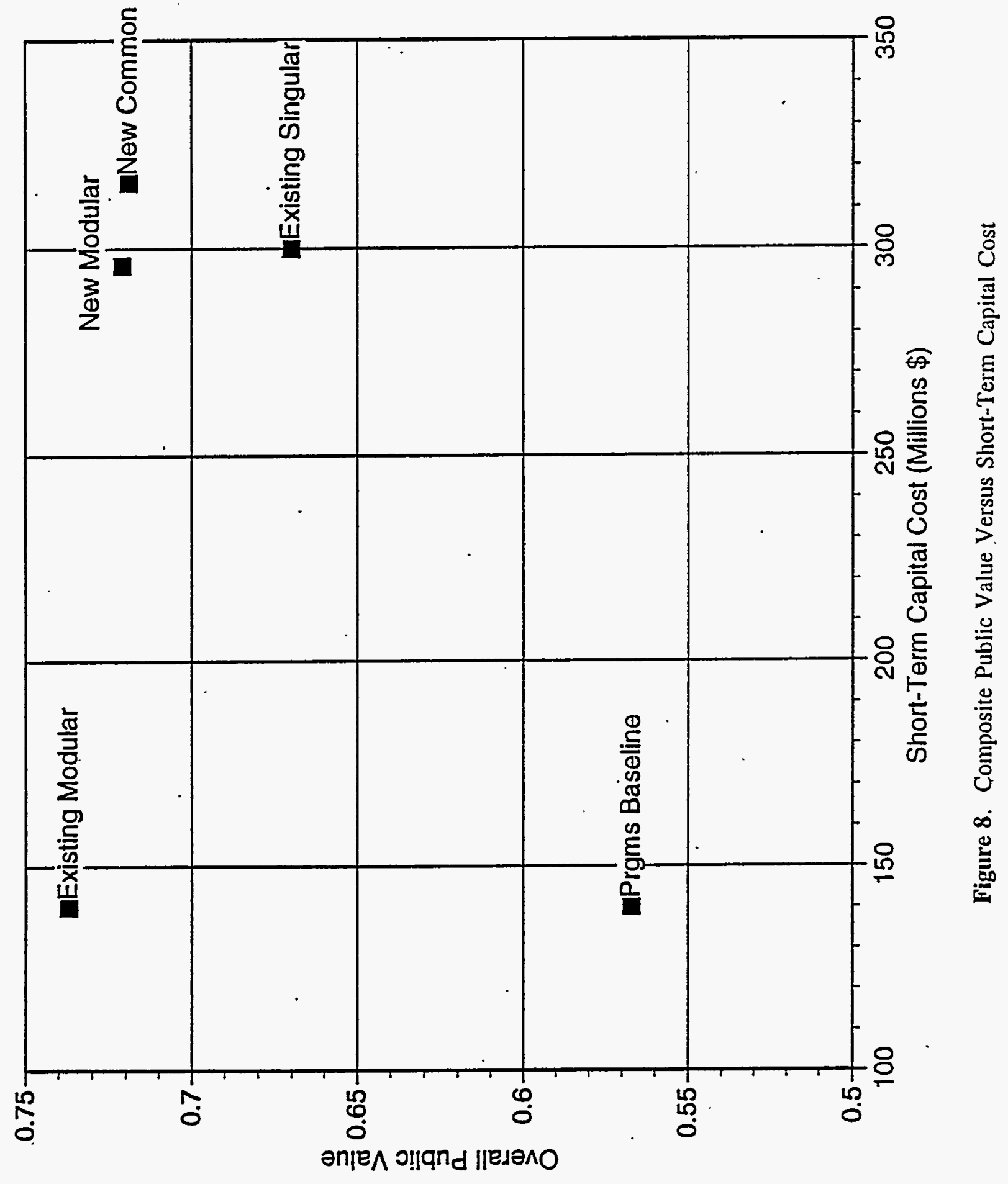




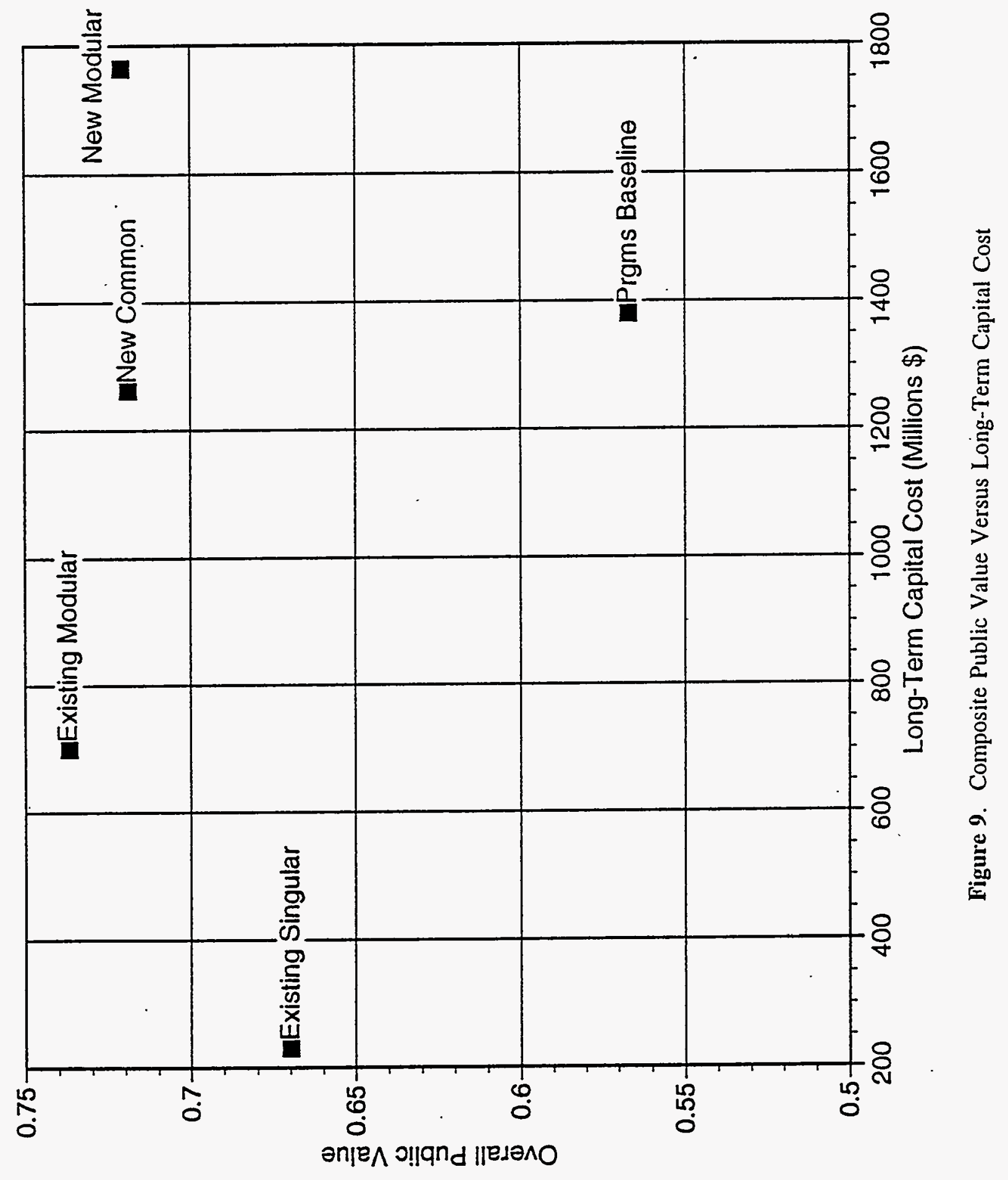




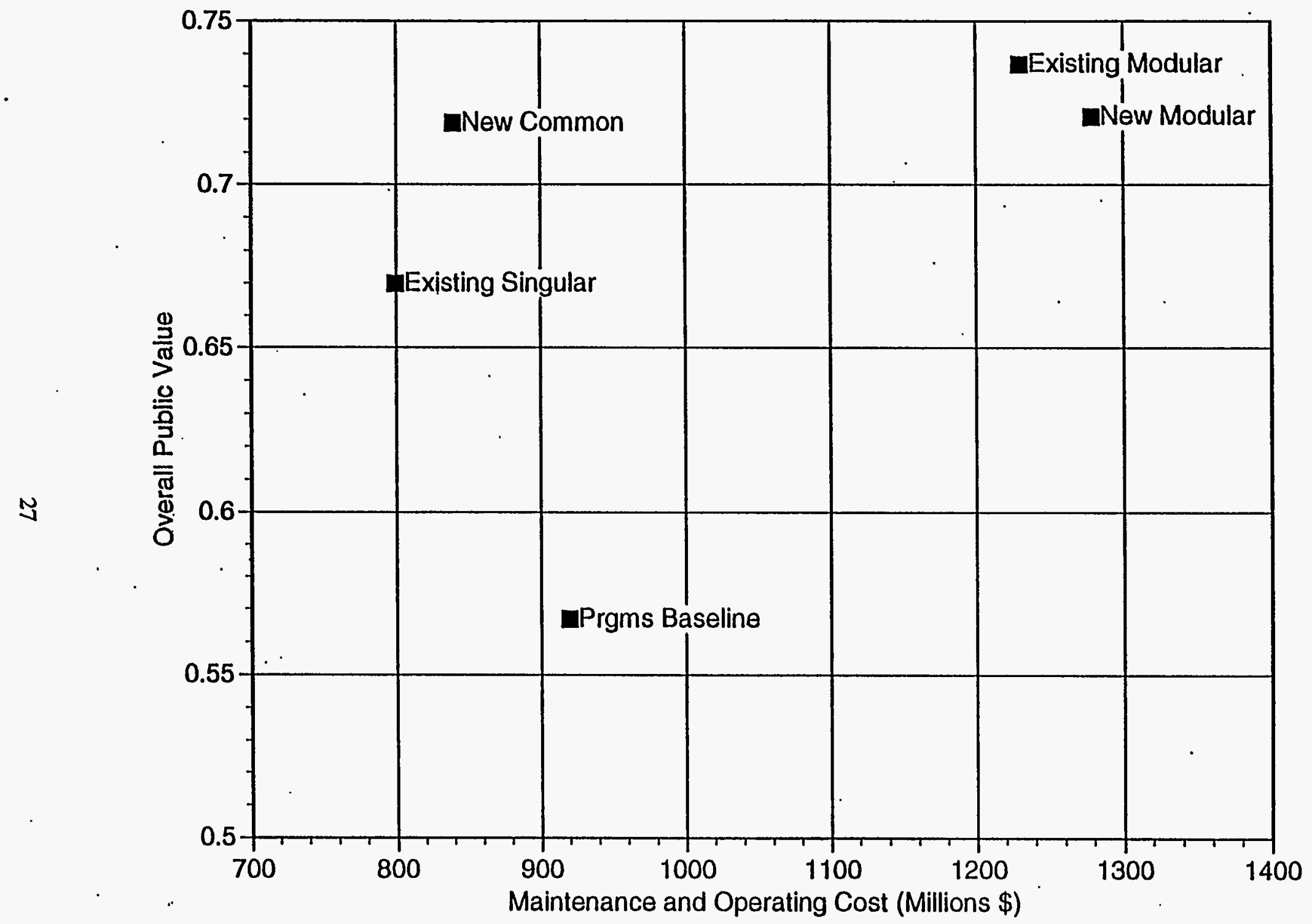

Figure 10. Composite Public Value Versus Maintenance and Operating Cost 
Periomance Procile for Exiscing Modular

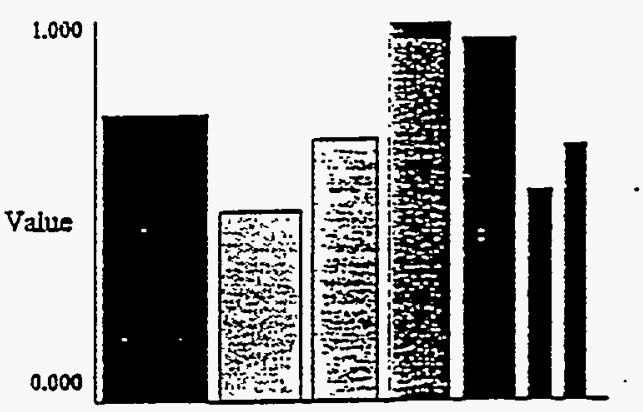

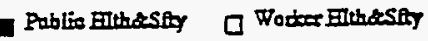

口 Socio onomis inot

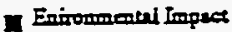

a Dero inezez of Promes

Performance Profile for Nert Common

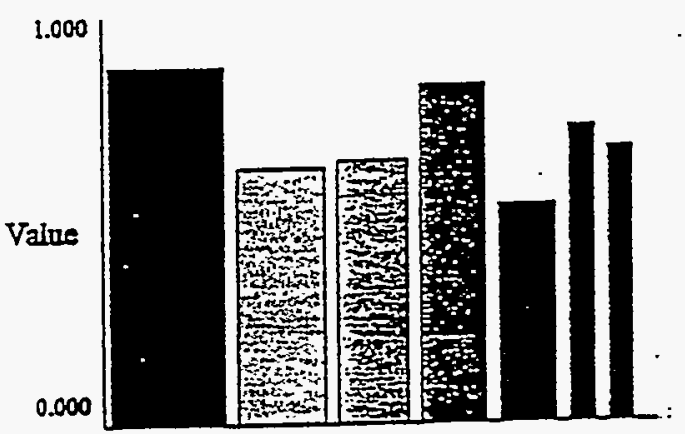

Pablic Elthestly

E Socioocosomic Inper

1 Eniramenal Impace

nero integ of Prgers
Q Woder Findesty

7 Schetrio

I. System Nenegeabilit

Peformance Profile for Program Baseline
Performance Profile for Netr Modular

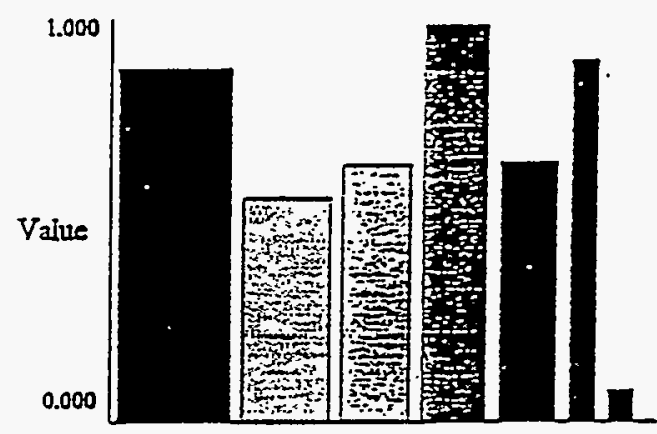

In Public Enthes:

Q Socioeconomic Inper

口 Worker Illthes Sty

Eniromeatai Inpara - I System Kanzesbilit

Demo Integ of Proms

Periomance Profie for Existing Singular

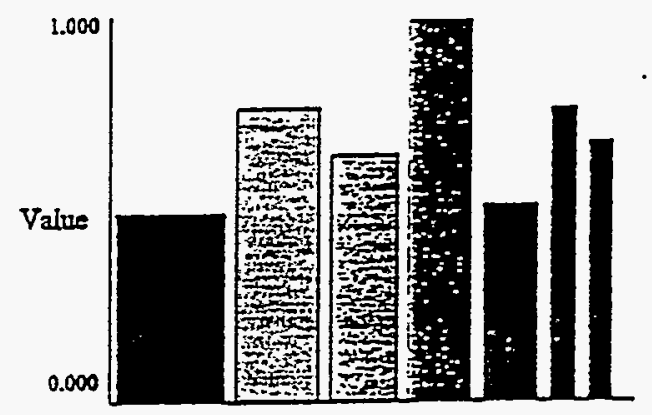

- Pablio Elthesay

Socionocosomio In

口 Tader Eltheses

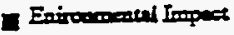

I Schodale

In Sy=en Mrongeribilis

11 Deoo Laney of Proms

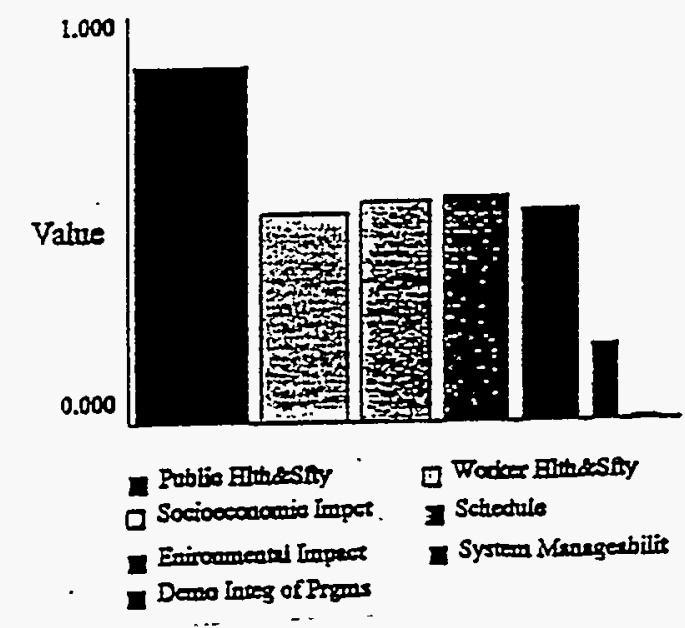

Figure 11. Performance Profile for Solid Waste Technical Options 
It is also interesting to study the Program Baseline's performance profile. Program Baseline is dominated by both Existing Modular and Existing Singular; however, it scores better than both of these on Public Health and Safety. Thus, even for dominated options there are tradeoffs.

A comparison of New Modular and New Common is also interesting. These options scored very closely overall ( 0.721 versus 0.719$)$, but there are trade offs when comparing them. They score close to each other on Health and Safety (actually New Modular scores slightly worse on Worker Health and Safety), and score the same on Socioeconomic Impact. New Modular does better on Schedule, Environmental Impact, and System Manageability; however, it does much worse on Demonstrate Integration of Programs (which is given little weight in the analysis).

The performance profiles shown in Figure 11 are in terms of the seven major categories of public values that were identified for the analysis. The discussion above is an analysis at the major-category level. Comparisons are also possible at the level of specific criteria. Figure 12 presents all ten possible paired comparisons analyzed at the level of specific criteria. For each of these ten comparisons, shown are the overall scores for the two technical options being compared, and the difference in their scores. It is this difference that each comparison accounts for. For example, when comparing Existing Modular with New Modular, this difference is 0.015 on a 0 -to- 1 scale. This difference is accounted for graphically by the bars for this comparison. The first bar represents this total difference, and it is in the Existing Modular column, showing that the overall difference favors Existing Modular. The other bars are ordered according to the magnitude of the differences, and their lengths are relative to the total difference in the first bar. The bars under Existing Modular are for those criteria that favor that option, and the bars under New Modular are for those criteria that favor that option. If all the bars favoring Existing Modular were joined end-for-end and compared to all the bars on the left similarly joined, the total length for Existing Modular would be longer by the amount of the total difference bar at the top. This analysis shows how the technical option's scores on specific criteria account for the overall differences, and shows the tradeoffs that are involved at the level of specific criteria.

Consider, for example, Existing Modular as compared with Existing Singular. These were the two non-dominated options identified in the cost-benefit analysis. Figure 12 shows that the overall difference is 0.067 in the favor of Existing Modular. Figure 12 also shows that the criteria favoring Existing Modular include Public Transportation Safety, Short-Term Environmental Impact, Making Available Areas of High Use Value, Public Radiation Exposure--Chronic, Long Term Environmental Impact, Public Chemical Exposure-Chronic, and Minimize D\&D Costs to Programs. Criteria that favor Existing Singular are Commuter Transportation Safety, Capture Economic Opportunities Locally, Integrated Use of Facilities, and miscellaneous other criteria.

\subsection{Sensitivity Analysis}

A sensitivity analysis was also carried out to explore the robustness of technical option rankings to changes in the weights assigned to major public value categories. This is separate from the sensitivity analysis to different value perspectives shown in Figure 5. The sensitivity analysis to weights placed on the major categories of public values is shown in Figure 13. Each panel in this figure shows the 


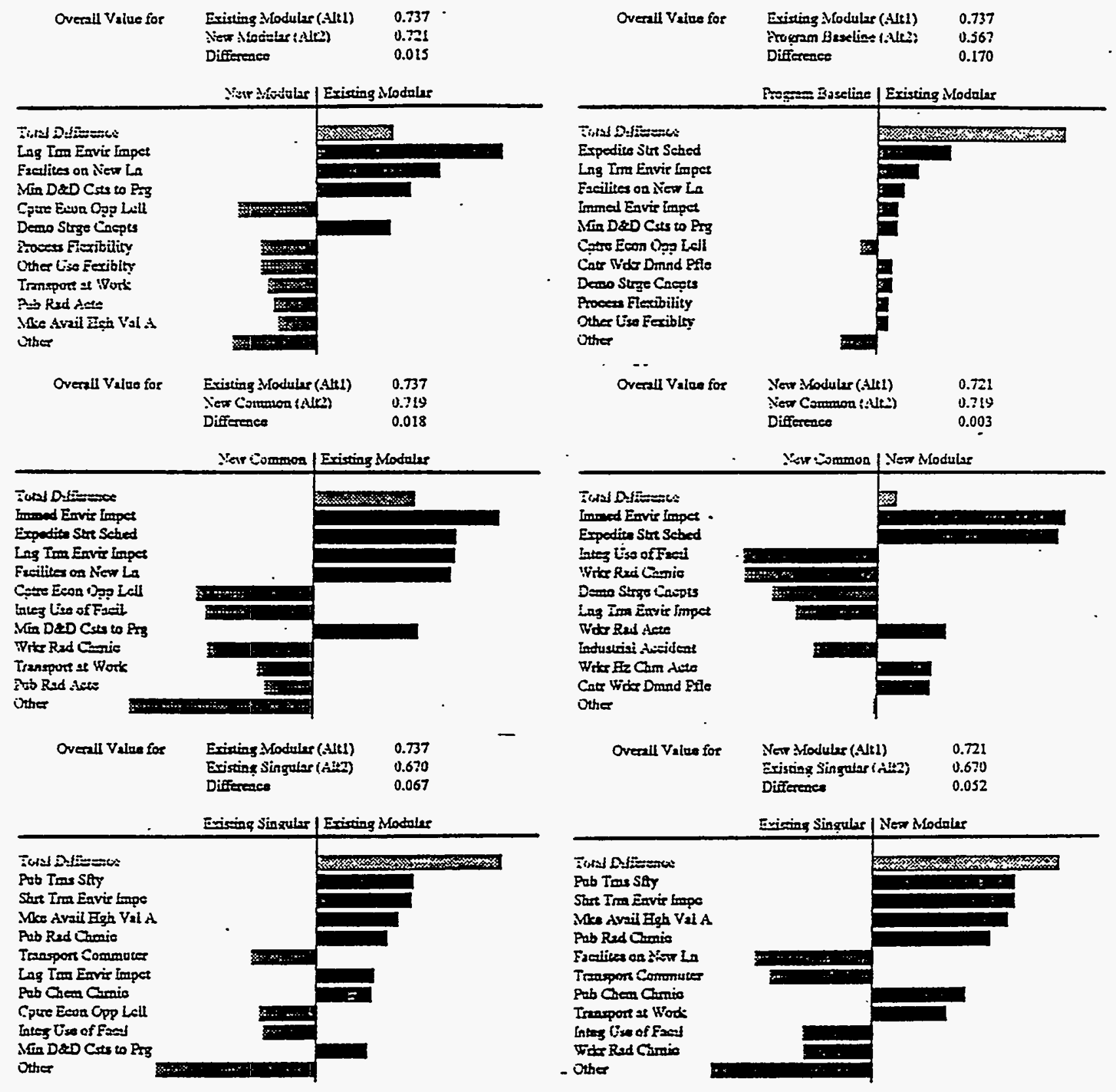

Figure 12. Paired Comparisons of Technical Options on Individual Criteria (page 1 of 2) 


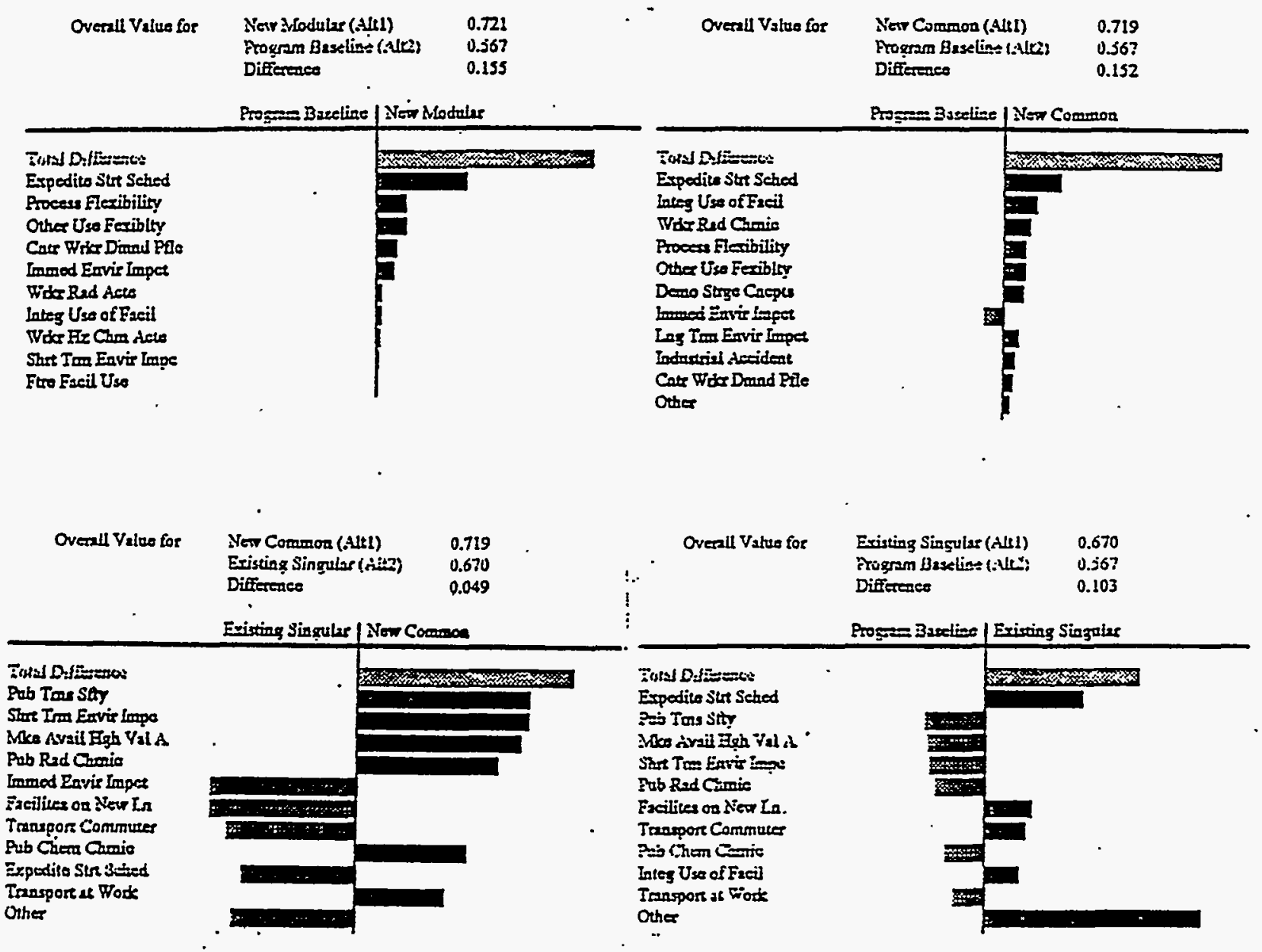

Figure 12. (page 2 of 2)

effect of varying the weight placed on one public value from $0 \%$ to $100 \%$ while keeping the weights on the other public values at their relative proportions.

Consider the panel for Worker Health and Safety shown in the upper right comer of the first page of Figure 13. The horizontal axis is the percent weight placed on this panel. The vertical axis is Overall Public Value on a 0-to-1.scale. The plotted lines show how the Overall Public Value for each of the technical options changes as a function of the weight placed on Worker Health and Safety. (Note that the order in which the lines appear in the legend is the same order in which they fall at $100 \%$ weight on the right, and that, because some of the coded lines were slightly corrupted in the reduction, this should be the basis for judging which lines correspond to which options.) The other vertical line, at $19 \%$, marks the weight used in the analysis. One can move this line mentally from side to side to see the impact of changing the weight on Worker Health and Safety. One can see from this panel that placing less weight on Worker Health and Safety would not change the order in which the technical options were ranked. If additional weight is placed on Worker Health and Safety, then at about $30 \%$ weight New Common becomes the highest ranked option, and at about $40 \%$ weight Existing 


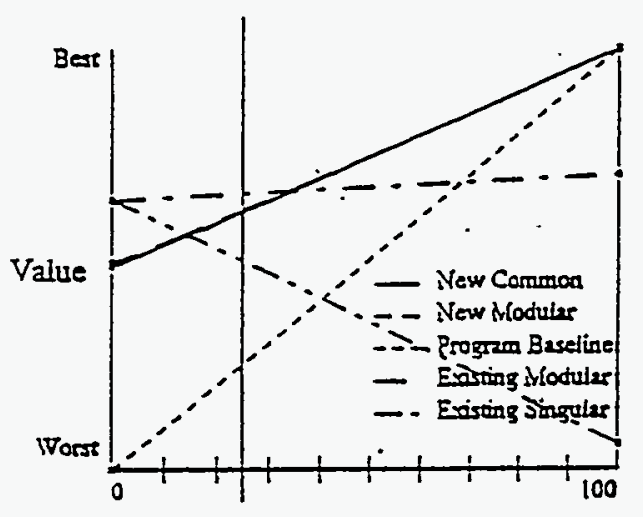

Percent of Weight on Public Hithesity Objective

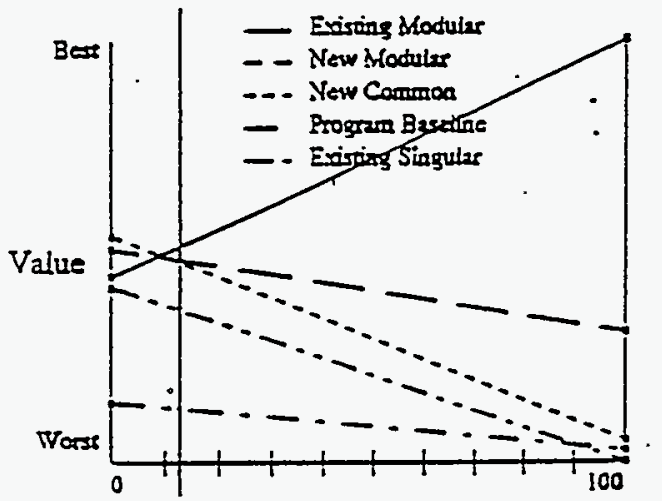

Percact of Weight on Enironmenal Inpest Objective.

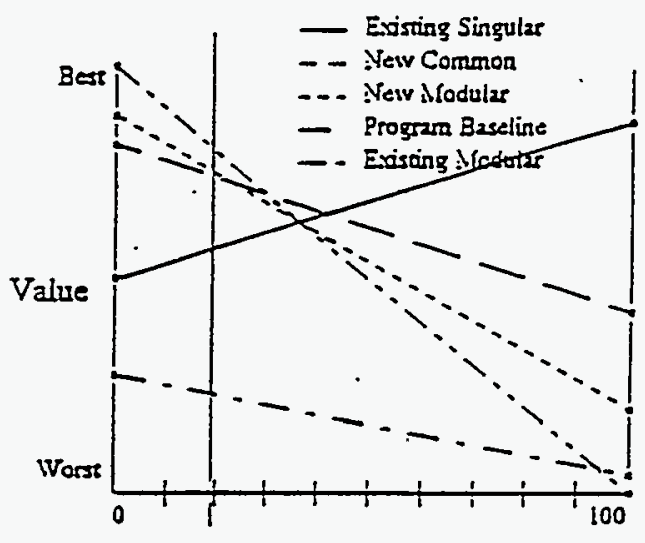

Pereent of Weight an Workes trithiesty Objecaive

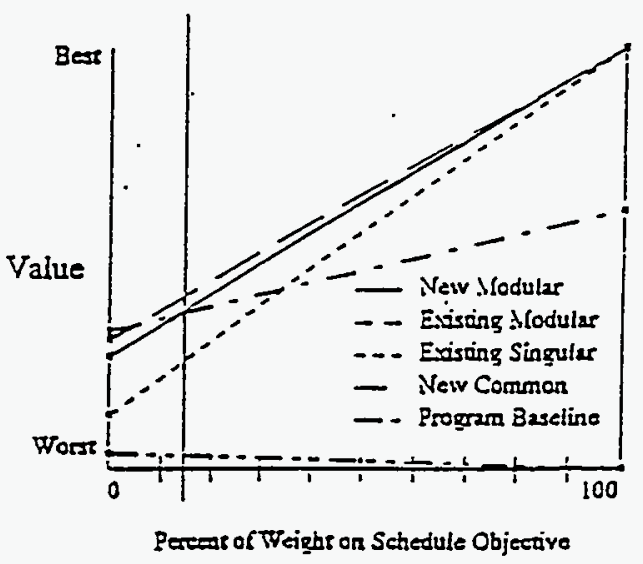

Figure 13. Sensitivity of Overall Public Value to Weights Placed on Specific Public Values (page 1 of 2) 

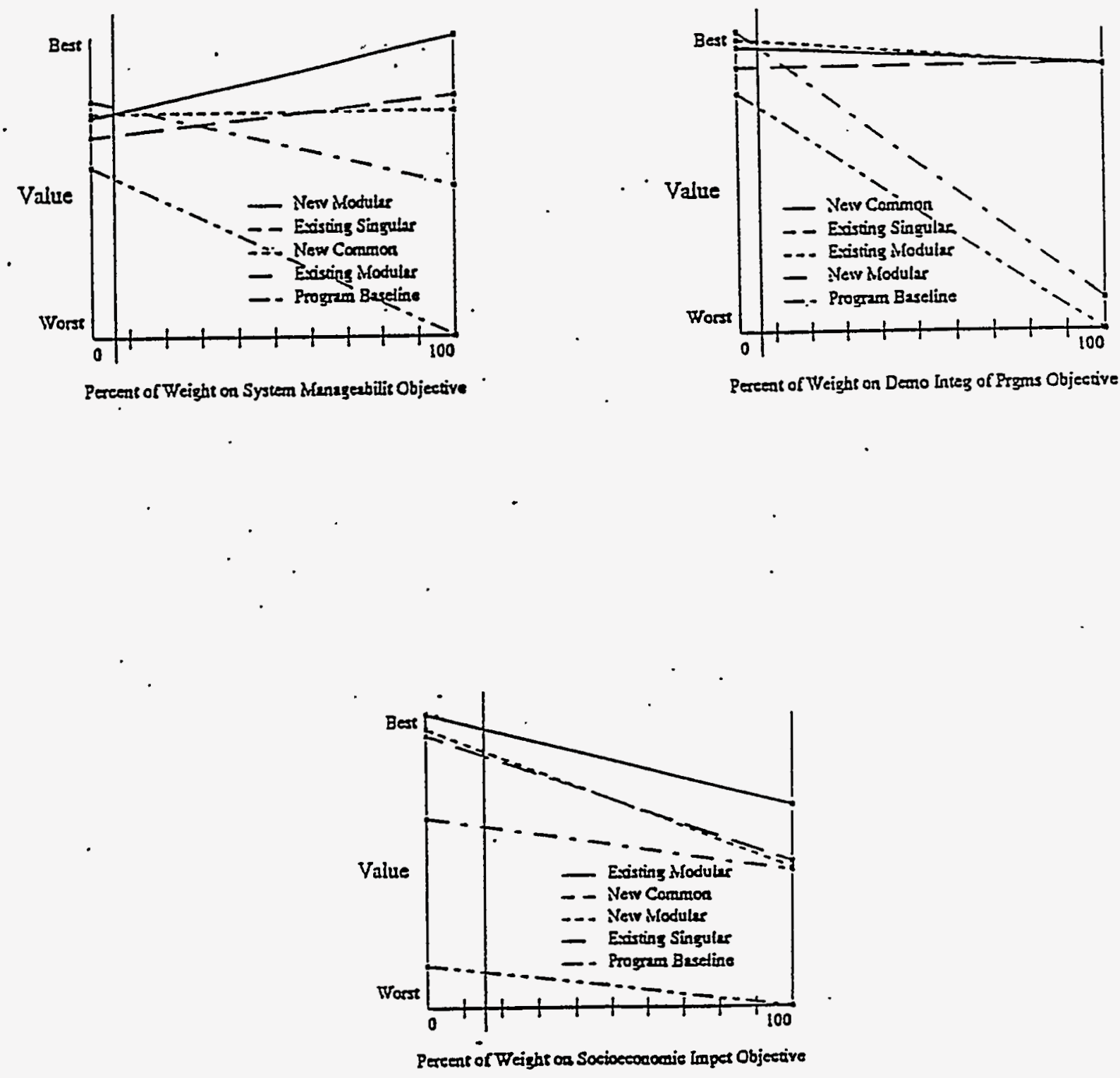

Figure 13. (page 2 of 2)

Singular becomes the highest ranked option and remains so regardless of how much additional weight is placed upon Worker Health and Safety. Thus, the ranking for Existing Modular is seen to be fairly robust within a wide range of weights for this particular objective.

Consider the final panel on the second page of Figure 11. Here it can be seen that Existing Modular is ranked first regardless of the weight placed on Socioeconomic Impact. If no weight were placed on Socioeconomic Impact, it would still score well enough on the other objectives to be ranked first, and if all the weight were placed on Socioeconomic Impact, it would still rank first because it scored highest on this objective. 
The rank for Existing Modular is fairly robust within the range of weights that were elicited. For each of the categories of public value, if one considers the range of weights placed on them by the four respondents as shown in Table 5, then Existing Modular remains the highest ranked technical option over the range of weights obtained for all but two of the categories. The two categories for which this does not hold are Environmental Impact and Demonstrate Integration of Programs. If the weight on Environmental Impact is decreased from $13 \%$ to $8 \%$, then Existing Modular becomes a very close third behind New Common and New Modular. If the weight on Demonstrate Integration of Programs is decreased from $6 \%$ to $3 \%$, then Existing Modular ranks second to New Modular. However, for either of these objectives, increasing rather than decreasing the weight does not change the order of the ranking within the range of all the weights that were elicited. This analysis, combined with the analysis from different value perspectives in which Existing Modular was always ranked first, seems to indicate that the ranking of first for Existing Modular is robust over a wide range of relative values.

\subsection{Risk Analysis}

The risk analysis is based upon the uncertainties described in this report. This analysis considers the risk to cost and schedule from three sources: (1) regulatory uncertainty, (2) uncertainty concerning the resolution of waste-processing issues, and (3) funding uncertainties. The results of this analysis are illustrated in Figures 14 and 15. Figure 14 shows the risk profile for cost in the form of a cumulative distribution function (CDF) on total cost, and Figure 15 shows the risk profile for schedule risk as a CDF on number of years until start up. The figures show CDFs for each of the technical options except for the Program Baseline. Risk data for the Program Baseline were not collected.

In order to understand the risk information contained in the CDF, consider Figure 14. Each point on a CDF represents the probability, on the $\mathrm{Y}$-axis, that the cost will be less than or equal to the amount on the $\mathrm{X}$-axis. Thus, for example, there is a $25 \%$ chance that the cost for New Common will be less than or equal to $\$ 2.9$ billion. The CDFs are based upon the possible scenarios illustrated by the decision tree shown in Figure 3, the data in Tables 2 through 4, and the estimated costs in Table 6. The CDFs were constructed by calculating, for each of the 96 possible paths through the decision tree, the probability of that combination of events occurring and the resulting net impact to cost and schedule if that combination of events did occur.

The CDFs in Figure 14 show at a glance the cost risk for each of the technical options. One can see, for example, that the risk associated with New Common is the greatest of all the options. The cost for this option could potentially be as little as $\$ 2.7$ billion to as much as $\$ 3.4$ billion-- a range of $\$ 700$ million. The cost risk for New Modular is considerably less -a range of approximately $\$ 300$ million. Also shown in Figure 14 are the expected (most likely or average) costs when risk are considered. Shown for comparison (in parentheses) are the estimated costs without consideration of risk, which were available from Table 6 as well as from Figure 6. Thus, as can be seen from Figure 14, the expected cost of Existing Modular is $\$ 2.144$ billion as compared with $\$ 2.1$ billion when risk is not considered. 


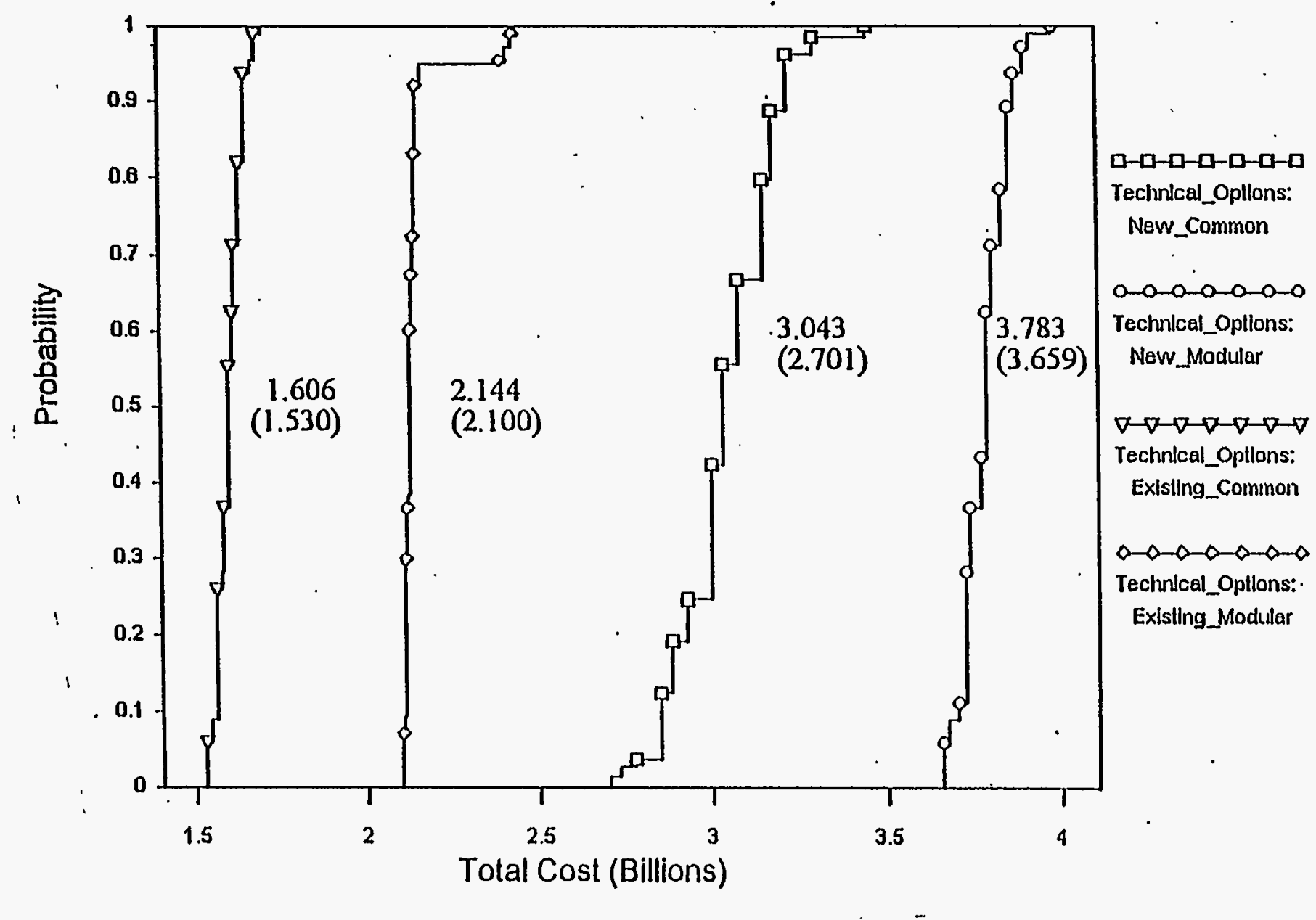

Figure 14. Risk Profile for Cost of Technical Options 


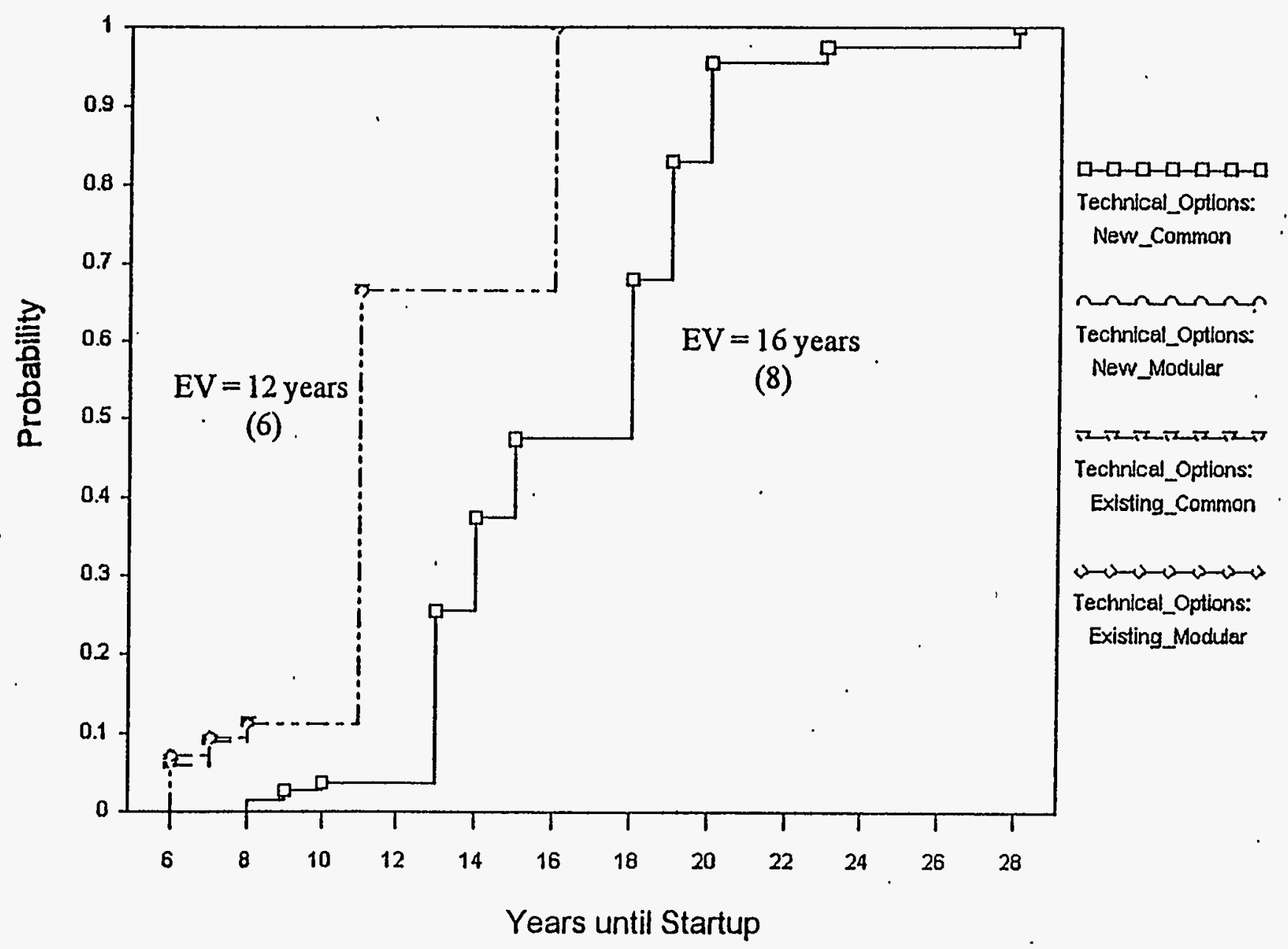

Figure 15. Risk Profiles for Schedule for Technical Options 
The large cost-risk for New Common is the cumulative risk from the perspective of all the sources considered. It involves a large single-item capital cost that would require a different approval process. Because all the processes would be in a single building, the resolution of specific processing uncertainties has the potential to impact all the processing. Similarly, with regulatory uncertainties, the failure to resolve specific issues has the potential to affect a wider scope of operations. Any of these potential delays can be costly, which is reflected in the greater range of potential costs as seen in Figure 14.

New Common is also the most risky from a schedule perspective. There is $5 \%$ chance that the start-up of a New Common facility could be delayed for more than 20 years. Figure 15 shows that the remaining three options have nearly identical risk profiles for Schedule. It is interesting to note that the risk analysis shows an expected start-up date of 16 years for New Common, and 12 years for the other three options. This compares to 8 and 6 years, respectively, for the estimates that did not consider risks. Thus, considering risk doubles the time required until start-up in every case.

\subsection{Discussion/Summary}

Figure 16 summarizes much of the analysis that has been described in the preceding sections. For each technical option this figure shows the overall public value and risk-based estimates of the option's costs. The horizontal lines show 90\% confidence intervals for cost. These represent the range in costs such that there is only one chance in twenty that they would fall above the range and one chance in twenty that they would fall below the range. (Estimates for the Programs Baseline are not risk-based and no range is given.) The vertical lines show the ranges in overall public value based upon the three value perspectives as depicted in Figure 5 and described in this report.

Thus, Figure 16 shows for each option the best estimates of its costs and overall value, as well as how far it may reasonably be thought to deviate from these estimates, given uncertainties in cost and value tradeoffs. As can be seen in the figure, there is no overlap of the options, even when considering their regions of uncertainties. This allows one to conclude that the analysis shown on Figure 7 , which was based on best estimates, still applies given uncertainties in cost and value tradeoffs. Consequently, we can be confident in the assertion that Existing Modular dominates all the technical options except for Existing Singular, and the fundamental decision is whether the additional value offered by Existing Modular is worth the additional costs.

The additional value offered by Existing Modular over Existing Singular is due to Public Health and Safety, Environmental Impact, and D\&D costs savings. The increase in value for Public Health and Safety is due to less potential for chronic exposure to either chemical or radiological contaminants, and increased Public Transportation Safety. The additional value for Environmental Impact is both short-term, as a result of being further from the Columbia River, and long-term, as a result of fewer acres and sites requiring D\&D; thus, there would be less potential for residual contamination. 


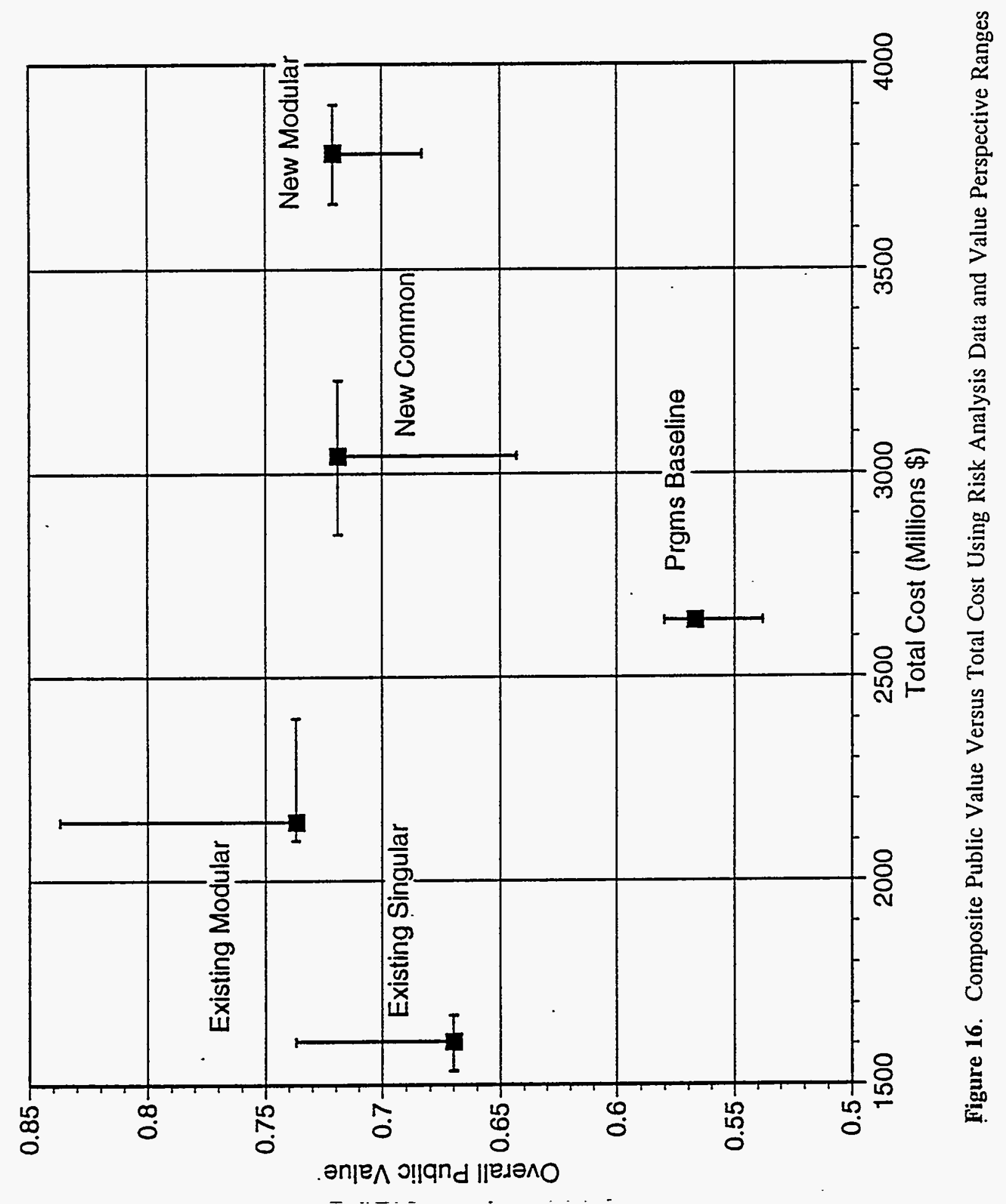


It should also be pointed out that while Existing Modular costs more overall than Existing Singular, the short-term capital costs and the $D \& D$ costs are lower. The greater costs are long-term capital and maintenance and operating which are spread out over the project's life, and therefore may be easier to bear.

It should also be pointed out that the estimated schedule and the risk profile for the schedule are the same for both Existing Modular and Existing Singular. However, the expected start date for all options doubles when risk is considered. This would seem to indicate a benefit from working closely with regulators in the near-term to resolve regulatory issues and processing uncertainties.

The cost risk does not appear to be as great for existing options as for new construction options especially New Common. It should, however, be pointed out that the cost uncertainties are most likely underestimated. The estimates are from potential impacts of external events, that is, events to some extent outside the control of the Solid Waste Program. The impacts from these events are important to consider; however, they are not the only source of uncertainty in the cost estimates. Cost estimates come from the aggregation of many individual estimated cost parameters, each of which has associated uncertainties. An analysis including these parametric uncertainties would show greater overall uncertainties for costs. Thus, the $90 \%$ confidence intervals for cost depicted in Figure 14 are most likely too narrow.

\subsection{References}

Armacost, L. L., D von Winterfeldt, J. Creighton, M. Robbershotte (1994), Public Values Related to Decisions in the Tank Waste Remediation System Program, Pacific Northwest Laboratory, Richland, Washington.

Keeney, R. L. and H. Raiffa (1976), Decisions with Multiple Objectives: Preferences and Value Tradeoffs, John Wiley \& Sons, New York.

Krantz, D. H. , R. D. Luce, P. Suppes and A. Tversky (1971), Foundations of Measurement (Vol. 1), Academic Press, New York.

National Safety Council. (1986), Accident Facts, 1986 Edition, Itasca, Illinois.

von Neumann, J. and O. Morgenstern (1947), Theory of Games and Economic Behavior, Princeton University Press, Princeton, New Jersey.

Wéstinghouse Hanford Company (WHC) (1995), Solid Waste and Materials System Alternatives Study. WHC-SD-WM-ES-341, Rev. 0, Richland, Washington. 
